OPEN ACCESS

Edited by:

Guillermo Raul Castro,

Consejo Nacional de Investigaciones

Científicas y Técnicas (CONICET),

Argentina

Reviewed by:

Xingshu $\mathrm{Li}$,

Fuzhou University, China

Houjuan Zhu,

Institute of Materials Research and Engineering ( $A * S T A R)$, Singapore

${ }^{*}$ Correspondence:

Havva Yagci Acar

fyagci@ku.edu.tr

Safacan Kolemen

skolemen@ku.edu.tr

Specialty section:

This article was submitted to Medicinal and Pharmaceutical Chemistry,

a section of the journal

Frontiers in Chemistry

Received: 10 May 2021

Accepted: 31 May 2021

Published: 24 June 2021

Citation:

Bilici K, Cetin S, Celikbas E, Yagci Acar $\mathrm{H}$ and Kolemen S (2021) Recent Advances in Cyanine-Based

Phototherapy Agents.

Front. Chem. 9:707876.

doi: 10.3389/fchem.2021.707876

\section{Recent Advances in Cyanine-Based Phototherapy Agents}

\author{
Kubra Bilici ${ }^{1}$, Sultan Cetin ${ }^{1}$, Eda Celikbas ${ }^{1}$, Havva Yagci Acar ${ }^{1,2,3 *}$ and Safacan Kolemen ${ }^{1,2,4,5 *}$ \\ ${ }^{1}$ Department of Chemistry, Koc University, Istanbul, Turkey, ${ }^{2}$ Surface Science and Technology Center (KUYTAM), Koc University, \\ Istanbul, Turkey, ${ }^{3}$ Graduate School of Materials Science and Engineering, Koc University, Istanbul, Turkey, ${ }^{4}$ Boron and Advanced \\ Materials Application and Research Center, Koc University, Istanbul, Turkey, ${ }^{5}$ TUPRAS Energy Center (KUTEM), Koc University, \\ Istanbul, Turkey
}

Phototherapies, in the form of photodynamic therapy (PDT) and photothermal therapy (PTT), are very promising treatment modalities for cancer since they provide locality and turn-on mechanism for toxicity, both of which are critical in reducing off-site toxicity. Irradiation of photosensitive agents demonstrated successful therapeutic outcomes; however, each approach has its limitations and needs to be improved for clinical success. The combination of PTT and PDT may work in a synergistic way to overcome the limitations of each method and indeed improve the treatment efficacy. The development of single photosensitive agents capable of inducing both PDT and PTT is, therefore, extremely advantageous and highly desired. Cyanine dyes are shown to have such potential, hence have been very popular in the recent years. Luminescence of cyanine dyes renders them as phototheranostic molecules, reporting the localization of the photosensitive agent prior to irradiation to induce phototoxicity, hence allowing imageguided phototherapy. In this review, we mainly focus on the cyanine dye-based phototherapy of different cancer cells, concentrating on the advancements achieved in the last ten years.

Keywords: cancer, photothemal therapy, photodynamic therapy, cyanine, synergistic therapy

\section{INTRODUCTION}

Photothermal therapy (PTT) and photodynamic therapy (PDT) are two different light-based therapeutic approaches for the treatment of various cancers (Jaque et al., 2014; Li et al., 2018b; Lan et al., 2019; Li X. et al., 2020; Wang et al., 2021). Generation of phototoxicity by the irradiation of photosensitive agents with no dark toxicity provides a long-desired locality in cancer treatment with an additional turn-on mechanism, which dramatically reduces the off-site toxicity. No cumulative toxicity, lack of resistance to multiple applications of phototherapies, and indications of reversal of multidrug resistance and influence on the metastatic tumor (Guo et al., 2017; Wei et al., 2019) accelerated the research efforts on phototherapy of cancer (Li et al., 2016; Jung et al., 2018; Dos Santos et al., 2019). PTT and PDT differ in the type of phototoxicity they generate. PTT is based on local temperature increase (Hu et al., 2018; Jung et al., 2018; Lv et al., 2020), and PDT is triggered by formation of reactive oxygen species, especially singlet oxygen $\left({ }^{1} \mathrm{O}_{2}\right)$ (Celli et al., 2010; $\mathrm{Li} \mathrm{X}$. et al., 2017; Li et al., 2018a) by irradiation of a photosensitizer (PS) at a molecule-specific wavelength.

A successful PS should fulfill the following requirements: 1) low dark toxicity, 2) strong absorbance at the excitation wavelength, 3) high ${ }^{1} \mathrm{O}_{2}$ quantum yield for PDT and high photo to thermal conversion efficiency for PTT, and 4) tumor-targeting ability to induce tumor-selective, strong phototoxicity (Jaque et al., 2014; Hu et al., 2018; Lan et al., 2019). Besides, absorbance at long 
wavelengths and phototoxicity generated at low power densities for safety and penetration depth are also critical in the clinical translation of these approaches.

As all therapeutic methods, PDT and PTT have limitations that need to be circumvented for broader use and improved therapeutic outcomes. One strategy to achieve this is to combine PDT with PTT, which seems to provide a synergistic effect (Bharathiraja et al., 2018; Bilici et al., 2019; Wang et al., 2019; Xia et al., 2019). Practically, if this can be achieved with a single PS, clinical translation would be relatively easy. The portfolio for such PSs is minimal, but cyanine dyes demonstrate such potential, and hence are subject to extensive research. In this review, we have summarized the PDT, PTT, and synergistic PTT + PDT approaches utilizing cyanine derivatives.

\section{PHOTODYNAMIC AND PHOTOTHERMAL THERAPY}

PDT has three critical components that play a role in cell death: light, photosensitizer (PS), and molecular oxygen $\left({ }^{3} \mathrm{O}_{2}\right)$. A PS is a molecule that transfers the absorbed energy from the light irradiation to form reactive oxygen species (ROS) or singlet oxygen (Kwiatkowski et al., 2018; Dos Santos et al., 2019). When treated with light, the PS absorbs the light and is excited from the ground state to the excited singlet state. This excited PS is unstable and can either emit the excess energy as light/heat or undergo intersystem crossing (ISC), whereby the spin inverts and transforms into its triplet state, which is relatively more stable than the singlet state. There are two alternative relaxation pathways for the triplet PS. It can react with an organic molecule from its surroundings, such as the cell membrane, and pick up a hydrogen atom or an electron to form radicals. These radicals then interact with oxygen and form ROS [e.g., superoxide anion $\left(\mathrm{O}_{2}{ }^{-}\right)$, hydrogen peroxide $\left(\mathrm{H}_{2} \mathrm{O}_{2}\right)$, and hydroxyl radical $\left.\left(\mathrm{HO}^{\bullet}\right)\right]$, which are the so-called type I reactions. In type II reactions, the triplet state PS can transfer its energy directly to the tissue oxygen and forms singlet ${ }^{1} \mathrm{O}_{2}$. Both of these reactions take place simultaneously, and due to its simplicity, it is believed that most of the PS undergoes Type II reaction (Kwiatkowski et al., 2018). However, the contribution from both mechanisms depends on the level of hypoxia, $\mathrm{pH}$, and the nature of the PS (Lucky et al., 2015). The effect of PDT on cancer cells can be summarized as follows: direct cytotoxic effect, damage to the vascular system, and stimulation of the immune system (Agostinis et al., 2011). As ROS has a very short half-life in aqueous solutions, only the cells in the PS range are affected by the PDT. This is advantageous to protect the surrounding healthy tissue but also limits the success of PDT when solid tumors are considered. It is worth underlining that the efficiency of the PDT highly depends on the PS type, tumor accumulation, administered dose, light exposure, oxygen availability, and singlet oxygen generation efficiency of the PS (Dolmans et al., 2003). Tumor hypoxia, quick clearance of PS, low efficiency, poor solubility or instability of the PS molecules, photobleaching, and day-light sensitization, plus the limited penetration depth of most commonly used red light, limit the clinical success of the PDT and require significant improvement (Deng et al., 2021).

In the case of PTT, irradiation of a PS causes local temperature increase by converting NIR light to heat, which may thermally ablate tumor cells or induce mild hyperthermia (Johannsen et al., 2005; Habash et al., 2007). Hyperthermia and thermal ablation treatments occur between 48 and $60^{\circ} \mathrm{C}$ temperature range, respectively (Habash et al., 2006; Habash et al., 2007). In hyperthermia, the local temperature increases to $41-48^{\circ} \mathrm{C}$ and cells should be kept at this temperature for about $15-60 \mathrm{~min}$ for the cell death; however, a few minutes at $48-60^{\circ} \mathrm{C}$ can kill the cells via thermal ablation (Habash et al., 2006). It is well established that thermal ablation triggers necrosis (Jaque et al., 2014). Although some organic molecules can be used as a PS for PTT (Lv et al., 2020), recently metal nanoparticles (Ke et al., 2011; He et al., 2014), metal oxide nanoparticles (Chu et al., 2013; Bilici et al., 2018), and quantum dots (Liang et al., 2018; Hashemkhani et al., 2020), especially with significant absorbance at near-infrared (NIR) for both better tissue penetration and safety due to its nonionizing nature (Jaque et al., 2014), are preferred. Light-to-heat conversion efficiency, dark toxicity, selective tumor accumulation, photostability, and effective heating of the whole tumor are factors to consider for PTT. Higher irradiation power requirement and tumor ablation causing necrosis of the healthy tissue on the path make low-temperature PTT more attractive but less effective if not assisted by a secondary treatment modality, preferentially PDT.

It has been reported that apoptotic cell death induced by PDT causes the release of signaling molecules to trigger immune cell death, which is quite important for complete treatment, treatment of metastatic tumor, and prevention of reoccurrence. On the other hand, PTT was reported to cause significant influence in suppression of drug resistance, increase in blood flow which would bring in oxygen to the hypoxic tumor, and improve permeability and hence improve penetration of PS into the tumor (Deng et al., 2021; Ding et al., 2021; Ming et al., 2021). All of the individual strengths of PTT and PDT point out not only a way to overcome their limitations but also a tremendous potential synergism to maximize the therapeutic effect.

\section{CYANINE DYES IN PHOTOTHERAPIES}

Several small organic molecules appeared as phototherapy agents for the treatment of various cancer types (Luo et al., 2016; Tan et al., 2017; Wang et al., 2019). Cyanine derivatives, either indocyanine green (Yuan et al., 2013) or heptamethine cyanine (Shi et al., 2016), are the most preferred and promising ones since they induce both PDT and PTT. Additionally, some of the cyanine derivatives can be targeted to mitochondria due to their cationic lipophilic nature (Weinberg and Chandel, 2015; Shi et al., 2016; Jung et al., 2017; Zhou et al., 2019). In the recent years, decorating these dyes with different heavy atoms improved the efficacy of the synergistic phototherapy by addressing the low 


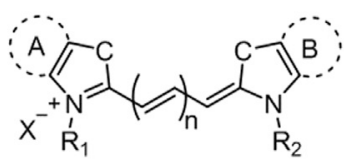

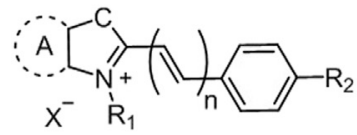<smiles>[Z]N(C)[N+]([Z])=CC=CC(=N)N(C)C</smiles>

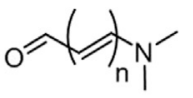

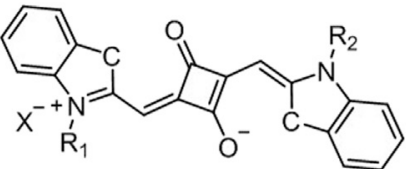

$\mathrm{n}=0,1,2,3$

$\mathrm{C}=\mathrm{CH}_{2}, \mathrm{CH}=\mathrm{CH}, \mathrm{C}\left(\mathrm{CH}_{3}\right)_{2}, \mathrm{~S}$, etc.

$A / B=$ absent, phenyl, naphthyl, etc.

$X=$ Counter anion

FIGURE 1 | Representative structures of cyanine fluorophores.

singlet oxygen generation capacity of the cyanine cores (Gorman et al., 2004; Atchison et al., 2017; Usama et al., 2018; Xu et al., 2019). In this review, we summarized PDT, PTT, and synergistic PTT + PDT approaches utilizing cyanine derivatives.

\section{Cyanines}

Cyanine dyes are characterized by two nitrogen heterocyclic rings connected via a $\pi$-conjugated polymethine chain (Figure 1) (Mishra et al., 2000; Shindy, 2012; Shindy, 2017). The heterocyclic structure can be pyrrole, imidazole, thiazole, benzothiazole, pyridine, or quinoline (Shindy, 2017; Gopika et al., 2021). Variations in the polymethine chain and nitrogen substituents on the heterocycles cause structural diversity in cyanine derivatives. The bridging polymethine chain is a conjugated chain formed by $\mathrm{sp}^{2}$ hybrid carbon atoms ending with a positive charge on the nitrogen through the displacement of $\pi$-electrons (Gopika et al., 2021). The cyanine family is very large; thus, subclassification is needed for its conjugates. Based on the terminal groups in the structure, they can be classified as closed chain cyanines, streptocyanines, merocyanines, squarylium cyanines, and hemicyanines (Figure 1) (Shindy, 2017; Gopika et al., 2021). Cyanine dyes can also be subcategorized based on the number of bridging methine chain as apocyanines (directly linked without any methine), monomethine cyanine, trimethine cyanine, pentamethine cyanine (dicarboxycyanine), and heptamethine cyanine (tricarbocyanine) (Shindy, 2012). Streptocyanines contain a non-heterocyclic aromatic moiety at both ends, while merocyanine dyes have an amino group in one end and a carbonyl group in other end, which are connected via polymethine chain (Kulinich and Ishchenko, 2009; León et al., 2016). Squarylium cyanines have a squaraine moiety in the center of the $\pi$-conjugation (Ferreira et al., 2013). Hemicyanine scaffolds feature a donor- $\pi$-acceptor $(\mathrm{D}-\pi-\mathrm{A})$ system as their structures have a terminal hydroxyl, alkoxy, or amino group as the electron donor and a nitrogen heterocyclic moiety with a positive charge as the electron acceptor group that are connected via a conjugated chain (Jędrzejewska et al., 2003). Cyanines usually exist in neutral and zwitterionic resonance forms with cationic and anionic moieties coexisting in the molecule. The absorption and emission maxima of cyanine dyes are affected by the polymethine bridge length as conjugated carbon chain with hetereocyclic units at the terminal position forces the formation of a linear shape (Shindy, 2017).

Cyanine core is among the most investigated fluorophores due to its favorable optical properties such as high molar absorptivity, narrow absorption/emission bands, reasonable fluorescence quantum yield, and most importantly, tunable fluorescence profile from the UV-vis to NIR range (Delaey et al., 2000; Mishra et al., 2000; Kulbacka et al., 2011; Bhattarai and Dai, 2017; Li Y. et al., 2020; Li et al., 2021). Additionally, the excellent biocompatibility and low toxicity make them a great candidate for biological studies spanning from imaging to therapy. Absorption maxima of cyanine derivatives can be tuned to the NIR region $(650-900 \mathrm{~nm})$ through easy structural modifications thanks to well-established cyanine chemistry. This is critical since NIR light is most suitable for biological applications as it provides deeper tissue penetration and light safety (Mallidi et al., 2016).

To that end, significant efforts have been put to develop effective methods for the synthesis of cyanine dyes and to improve their photophysical properties for biological applications (Figure 2) (Narayanan and Patonay, 1995; Li et al., 1997; Jędrzejewska et al., 2003; Kulinich and Ishchenko, 2009). The most popular method for the synthesis of cyanine dyes is the condensation of aromatic quaternary ammonium salts with different reagents in the presence of a base. For example, trimethine cyanine can be obtained through condensation of quaternary ammonium salts with trimethyl orthoformate resulting in different trimethine cyanine fluorophores depending on the $-\mathrm{R}$ groups in the heterocycle. General strategy for pentamethine cyanine synthesis is the condensation of quaternary ammonium salts with bis-aniline-conjugated polymethine chain bearing different meso-substituents. Heptamethine-cyanine dyes with mesochlorine substitution and related heptamethine-cyanine dyes without substitution on the vinyl chain can be synthesized using condensation of quaternary indolium salts as shown in Figure 2 ( $\mathrm{Li}$ et al., 1997). Additionally, hemicyanine-like structures can be obtained by the condensation of heterocyclic bases (Fischer's base) containing activated methyl groups with unsaturated benzaldehydes (Jędrzejewska et al., 2003).

Cyanine fluorophores, especially those excited with a light in the NIR, are studied for both fluorescence imaging and phototherapeutic effect, which renders them as 

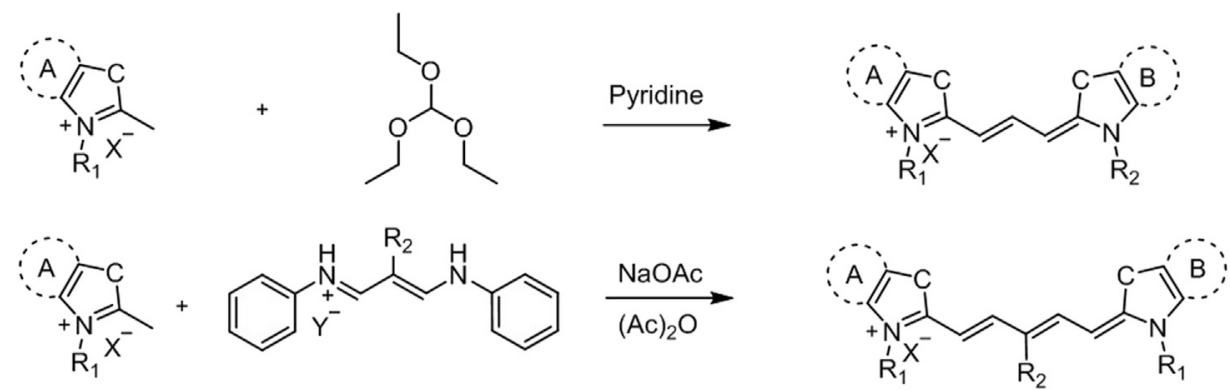

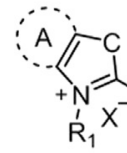

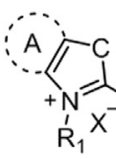

$\mathrm{A} / \mathrm{B}=$ absent, phenyl, naphthyl, etc.<smiles>O=CC1=C(Cl)/C(=C/O)CCC1</smiles>

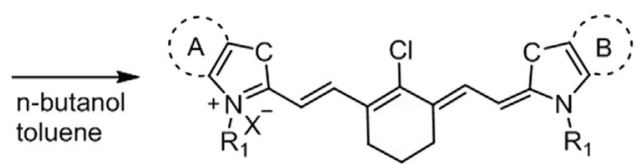

base

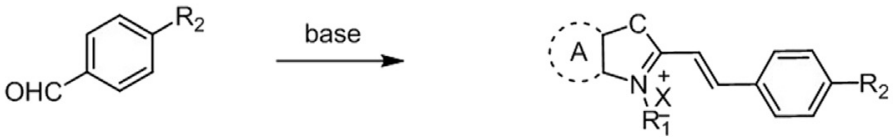

$\mathrm{C}=\mathrm{CH}_{2}, \mathrm{CH}=\mathrm{CH}, \mathrm{C}\left(\mathrm{CH}_{3}\right)_{2}, \mathrm{~S}$, etc. $\mathrm{X}, \mathrm{Y}=$ Counter anion

FIGURE 2 | General synthetic approaches for cyanine derivatives (Li et al., 1997).

phototheranostic agents (Jung et al., 2018; Chen et al., 2019; Li et al., 2021). However, the phototherapeutic efficacy of conventional cyanine dyes is not adequate due to low photoconversion efficiency, poor photostability, and undesired aggregation in aqueous solution. Therefore, a number of studies have been carried to improve these properties, including conjugation with other therapeutic agents to enhance its therapeutic efficacy and broaden its therapeutic modality (Zhao et al., 2019; Ebaston et al., 2021; Li et al., 2021). For the phototherapeutic applications, especially PDT, improvement of ${ }^{1} \mathrm{O}_{2}$ generation efficiency is usually achieved by introduction of heavy atoms (iodine, bromine, selenium, etc.) to favor ISC as a result of enhanced spin-orbit coupling (Santos et al., 2005; Atchison et al., 2017; Cao et al., 2019; Ebaston et al., 2021). For example, iodination on the heterocyclic core in heptamethine cyanine increases the ISC efficiency through heavy-atom effect with resulting cultivated therapeutic efficacy (Shi et al., 2016; Huang and Luo, 2020). On the other hand, it is also possible to achieve high singlet oxygen yield with heavy-atom-free cyanine conjugates by incorporating them with an ISCpromoting moiety such as tetramethylpiperidinyloxy (TEMPO) (Yang et al., 2020).

Another issue with the cyanine core is its chemical instability under light irradiation. So far, although photoconversion of cyanine fluorophores has been known, the underlying mechanism and the species involved in these photoconversion reactions are still unclear (Shindy, 2017). A recent study by Schnermann's group showed that heptamethine cyanines are converted into pentamethine cyanines, which, in turn, are converted to trimethine cyanines through light irradiation (Matikonda et al., 2021).
Some other common limiting factors such as low water solubility and ease of self-aggregation have been tried to be solved by introducing hydrophilic units (e.g., sulfonate groups) to the nitrogen-containing heterocycles. In this direction, a number of phototheranostic agents based on cyanine core with improved water solubility and therapeutic efficiency have been developed successfully so far (Luo et al., 2016; Li S. et al., 2017; Huang and Luo, 2020; Gunduz et al., 2021).

\section{Cyanine-Based Photosensitizers in Phototherapies}

Meng et al. developed a small molecule probe RhoSSCy (Figure 3A) by conjugating 5 'carboxyrhodamines (Rho) and IR765, which offers thiol/pH dual-sensing, tumor-targeting, NIRF/photoacoustic (PA) dual-modal imaging, and PDT potential. The fluorescence response of RhoSSCy was evaluated on MCF7 cells, and a strong fluorescence was observed in the presence of $\mathrm{GSH}$ at low $\mathrm{pH}(\mathrm{pH}=6)$. PA imaging revealed that RhoSSCy accumulated in tumor tissue in $4 \mathrm{~h}$ and reached its maximum in $15 \mathrm{~h}$ in MCF7 cells (Figure 3D). The irradiation of RhoSSCy at 660-nm laser wavelength $\left(30 \mathrm{~mW} / \mathrm{cm}^{2}\right)$ for $5 \mathrm{~min}$ caused significant cell death at $10 \mu \mathrm{M}$ and almost complete cell death at $40 \mu \mathrm{M}$ (Figure 3B). A significant tumor suppression was observed after two weeks of irradiation at $100 \mathrm{~mW} / \mathrm{cm}^{2}$ (Figure 3C) (Meng et al., 2017b).

Zhen et al. developed a galactose-caged NIR hemicyanine dye (CyGal-P), which is linked with a PEG chain, for image-guided cancer therapy and compared its potential with parent $\mathrm{CyGal}$ core (without PEG) on ovarian cancer, where $\beta \mathrm{Gal}$ is known to be 

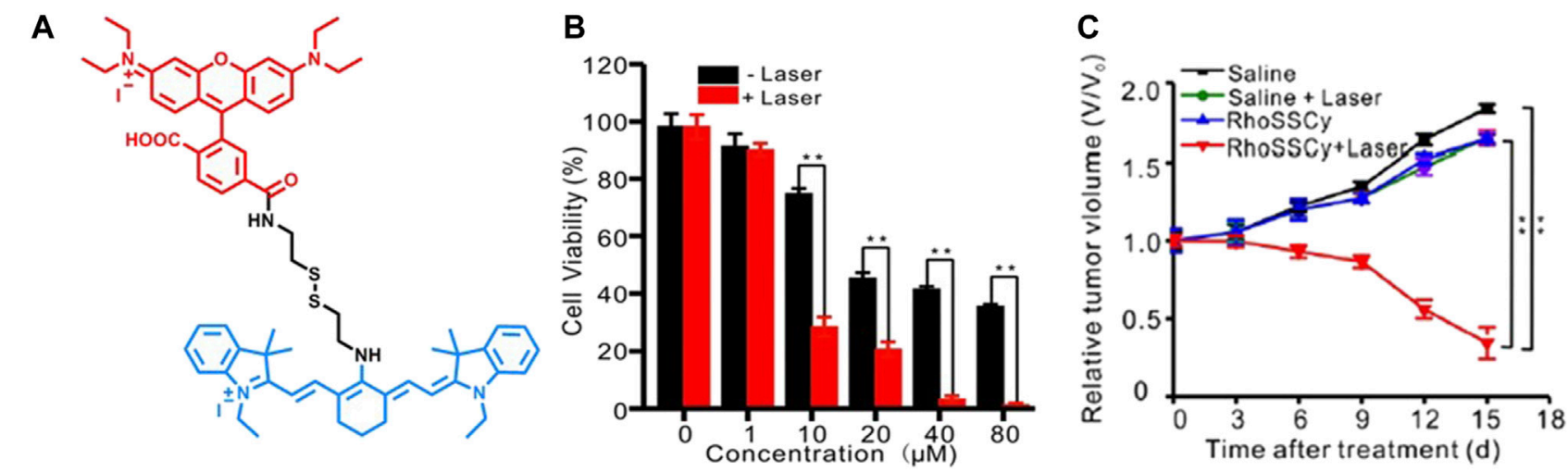

D
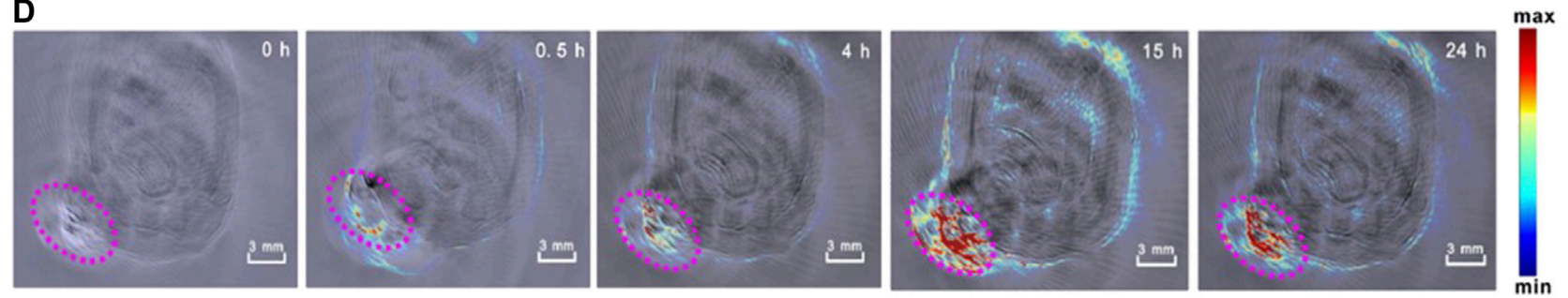

FIGURE 3 | (A) Representative structure of RhoSSCy, (B) the effect of RhoSSCy-induced PDT on MCF7 cell viability with different PS concentrations, (C) the tumor growth of MCF7 xenograft tumors after different treatments within 15 days, and (D) PA imaging of a tumor-bearing nude mouse at different hours. (Reproduced from ref. Meng et al. (2017b) with permission from Ivyspring, copyright 2017.)

A

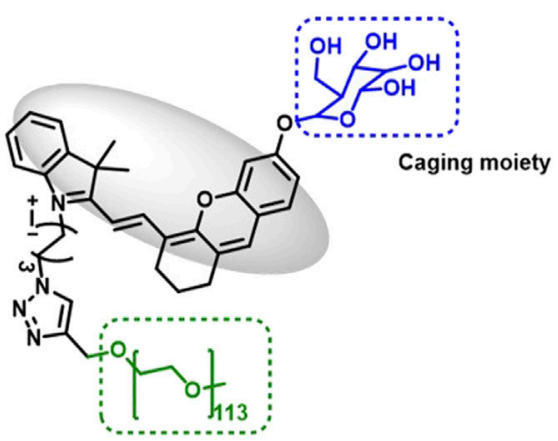

CyGal-P

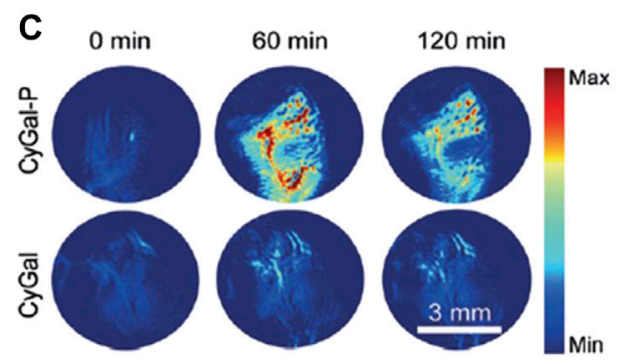

B

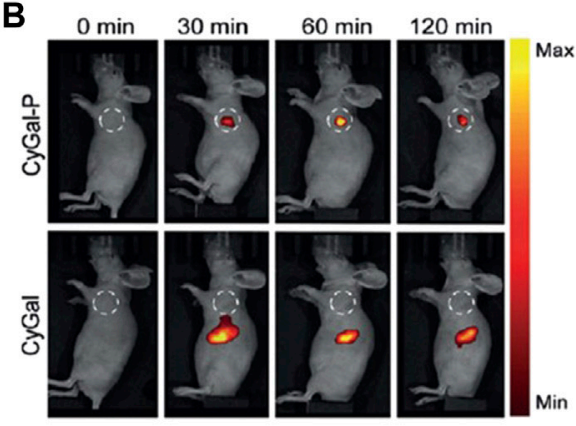

D

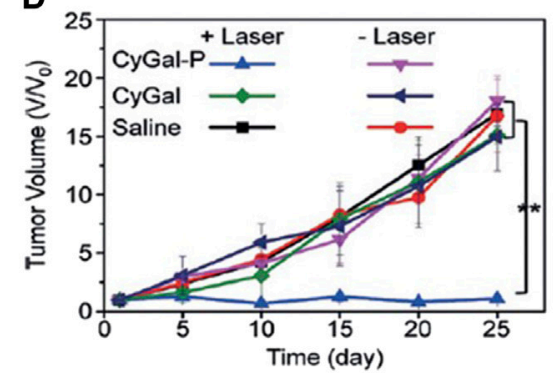

FIGURE 4 | (A) Representative structure of CyGal-P, (B) fluorescence, and (C) PA images of SKOV3 tumor-bearing living mice after intravenous injection of CyGal and CyGal-P at different times at $300 \mu \mathrm{M}$, and (D) tumor growth in SKOV3 tumor-bearing mice after laser irradiation of CyGal and CyGal-P. (Reproduced from ref. Zhen et al. (2018) with permission from Wiley, copyright 2018.) 
<smiles>[X]c1ccc2c([Y]/c(=C\C3=C([O-])/C(=C\c4ccc5ccccc5[n+]4C)C3=C(C)C#N)n2[R])c1</smiles>

1a: $\mathrm{A}=\mathrm{C}\left(\mathrm{CH}_{3}\right)_{2} \mathrm{X}=\mathrm{H} \quad \mathrm{R}=\mathrm{CH}_{3}$

1b: $A=S \quad X=H$

1c: $A=S \quad X=H$

1d: $A=S \quad X=B r$

1e: $A=S e \quad X=H$
$\mathrm{R}=$<smiles>CCCCOC(=O)CCCC(C)(C)C</smiles>
R $\{$ s

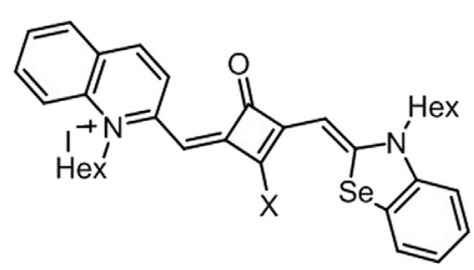

2a: $X=0^{-}$,

2b: $\mathrm{X}=\mathrm{OCH}_{3}$,

2c: $\mathrm{X}=\mathrm{NH}_{2}$,

2d: $X=\mathrm{NHCH}_{3}$

FIGURE 5 | Representative structures of dyes in (A) D Martins et al. (2020) and (B) Lima et al. (2020).

overexpressed Figure 4. The irradiation of CyGal-P with 680-nm laser wavelength $\left(0.6 \mathrm{~W} / \mathrm{cm}^{2}\right)$ for 5 min caused almost complete cell death on SKOV 3 cell line as a result of PTT action, while there was no cell death after irradiation of CyGal. The in vivo NIRF and photoacoustic images showed that CyGal-P accumulated in the tumor in $60 \mathrm{~min}$; however, the accumulation of CyGal was very low in the tumor region. In in vivo animal models, complete tumor elimination was achieved without any abnormalities (Zhen et al., 2018).

The PDT efficacy of mitochondria-targeted NIR $\mathrm{CYBF}_{2}$, a boron difluoride complex-modified cyanine, was evaluated on MCF7 cells based on various concentrations and light doses. $\mathrm{CYBF}_{2}$-treated MCF7 cells showed strong fluorescence after $10 \mathrm{~min}$, suggesting quick internalization of $\mathrm{CYBF}_{2}$ by cancer cells. The $\mathrm{IC}_{50}$ value was found to be $2 \mu \mathrm{M}$ under $660-\mathrm{nm}$ laser irradiation $\left(90 \mathrm{~J} / \mathrm{cm}^{2}\right.$ light dose), and enhanced toxicity was observed with higher light doses and agent concentrations. The irradiation of $\mathrm{CYBF}_{2}$ provided cell death by causing severe mitochondrial depolarization (Zhao et al., 2019).

Reis et al. introduced two articles on photophysical and photochemical properties and the photobiological activity of squaraine cyanine dyes (1a, b, c, d, and e) (Figure 5A). These dyes exhibited sharp absorption in the NIR region in several organic solvents and broad absorption between $600-800 \mathrm{~nm}$ in aqueous buffered solutions (PBS and DMEM). Singlet oxygen quantum yield of dyes were reported within the range of 0.01-0.08 in chloroform with moderate light stability. Furthermore, a cell viability assay was performed on human colorectal adenocarcinoma (Caco-2) and human hepatocellular carcinoma (HepG2) to show in vitro photocytotoxicity activity. It was reported that $1 \mathrm{a}, 1 \mathrm{c}$, and 1e displayed comparably higher cytotoxicity with $\mathrm{IC}_{50}$ value below $0.5 \mu \mathrm{M}$ in both cell lines (D Martins et al., 2020). In a follow-up study, Reis's group developed a series of quinoline- and benzoselenazole-derived unsymmetrical squaraine cyanine dyes (2a, b, c, and d) (Figure 5B). Similarly, these dyes have sharp absorption band between 636 and $733 \mathrm{~nm}$ in organic solvents, and broader signals in aqueous solutions associated with the formation of aggregates and low singlet oxygen yield. In vitro phototoxicity of dyes was proven in breast cancer cell lines BT-474 (human ductal breast carcinoma) and MCF7 (human breast adenocarcinoma derived from pleural effusion) with reasonable $\mathrm{IC}_{50}$ values (up to $0.6 \mu \mathrm{M})$. As an improvement, these dyes were found to be photostable, highlighting the stability of the zwitterionic dyes and improved the singlet oxygen quantum yields (Lima et al., 2020).

An NIR fluorescent heptamethine cyanine dye, IR-822, with a high extinction coefficient was conjugated with a $\mathrm{pH}$-sensitive receptor $\mathrm{N}^{1}$-(pyridin-4-ylmethyl)ethane-1,2-diamine (PY) to increase its tumor accumulation and imaging capability. This molecular probe (Figure 6A) was designed to work as a switch-on in the acidic tumor microenvironment which allowed the enhancement of the NIR imaging in vivo. The conjugate had a strong absorption in the NIR, and a peak shifted from 637 to $792 \mathrm{~nm}$ with increasing $\mathrm{pH}$ value, while showing a good photothermal effect. The probe was tested on MCF7 cells and after incubation for $24 \mathrm{~h}$, no significant cytotoxicity was observed up to $100 \mu \mathrm{g} / \mathrm{ml}$ concentration. The flow cytometry revealed that the fluorescence signal from the IR-PY reached its maximum value just after $4 \mathrm{~min}$. The targeting effect was investigated with both healthy and cancerous liver (Lo2 and HepG2), lung (MRC-5 and A549), kidney (293 and A498), and breast (MCF-10A and MCF7) cell lines, and the data indicated that the cellular uptake was significantly higher in the tumor cell lines. Finally, they examined the in vivo tumor targeting and NIR imaging with tumor-bearing nude mice upon addition of $40 \mu \mathrm{g} / \mathrm{ml}$ IR-PY. After $10 \mathrm{~h}$ of injection, the mice showed strong NIR fluorescence signal on the tumor tissue and after $14 \mathrm{~h}$, the fluorescence signal reached a plateau (Figure 6B). At 14-h time point, the mice were further treated with a low-powered NIR laser $\left(808 \mathrm{~nm}, 0.4 \mathrm{~W} / \mathrm{cm}^{2}\right)$ for $3 \mathrm{~min}$, and it was shown that tumors in mice treated with IR-PY plus laser exhibited stronger hemorrhagic injury and severe necrotic tissue than the control group with no tumor recurrence for 30 days after treatment (Figures 6C,D) (Meng et al., 2017a). 
A
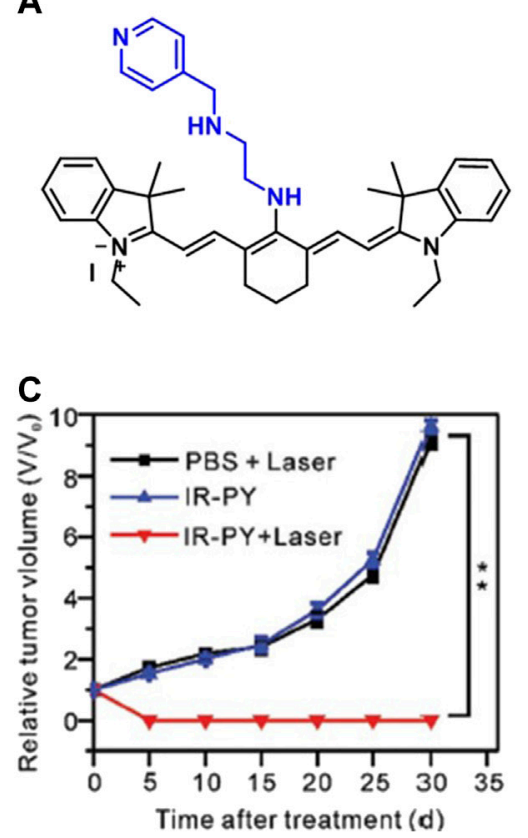

B

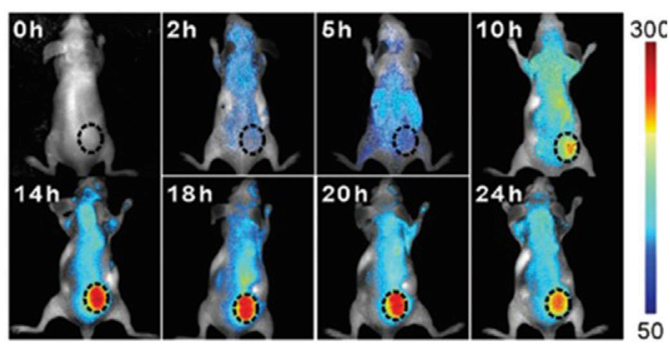

D

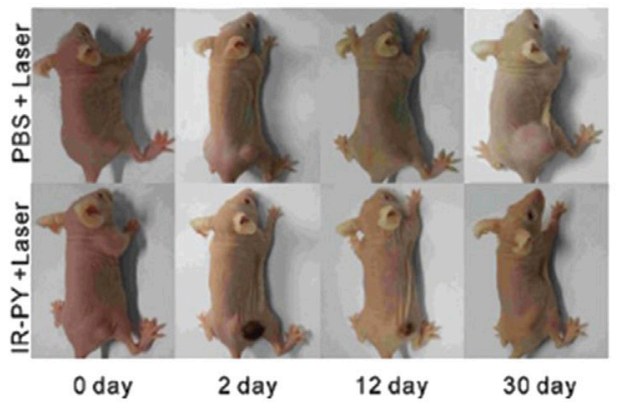

FIGURE 6 | (A) Structure of IR-PY, (B) NIRF images of MCF7 tumor-bearing living nude mice after injection of IR-PY at different times, (C) the tumor growth, and (D) representative images of mice bearing after different treatments. (Reproduced from ref. Meng et al. (2017a) with permission from RSC, copyright 2017.)

Benefiting from the strong absorption and broad NIR emission (700-1,300 nm) of IR-820, Feng et al. developed an excretable NIR-II imaging and NIR-I PTT probe using IR-820 for cardiovascular imaging and therapy (Figure 7) (3). The probe was utilized without any surface modification in vivo by intravenous injection of $0.5 \mathrm{mg} / \mathrm{ml}$ dose. The data showed good biocompatibility by clearing out from the liver in 5 weeks and NIR-II fluorescence imaging-guided photothermal therapy on the subcutaneous tumor of mice. Additionally, in vivo cerebrovascular imaging of mice was conducted, achieving high spatial resolution $(6.061 \mu \mathrm{m})$ even at the depth of $\sim 800 \mu \mathrm{m}$ (Feng et al., 2019).

Using high targeting ability of the sorbitol moiety, a bifunctional heptamethine cyanine fluorophore, sorbitol-ZW800 conjugate, was developed as a PTT agent for in vivo cancer imaging and therapy (Figure 7). A temperature increase of $58.7^{\circ} \mathrm{C}$ was observed after the NIR laser irradiation $\left(1.1 \mathrm{~W} / \mathrm{cm}^{2}\right)$ for $5 \mathrm{~min}$. The photothermal conversion efficiency was calculated as $32.6 \%$ which was deemed to be relatively higher than many inorganic phototherapy agents. In vivo studies were conducted with HT-29 tumor-bearing mice using a single dose $(10 \mathrm{nmol}, 0.4 \mathrm{mg} / \mathrm{kg})$ of injection. Fluorescence signal on the tumor tissue reached its maximum value in $2 \mathrm{~h}$ and gradually decreased, showing good imaging potential. Additionally, in vivo PTT effect was assessed by treating the tumor-bearing mice with $10 \mathrm{nmol} 0.4 \mathrm{mg} / \mathrm{kg}$ sorbitol-ZW800 conjugate $2 \mathrm{~h}$ prior to laser irradiation at $808-\mathrm{nm}$ laser $\left(1.1 \mathrm{~W} / \mathrm{cm}^{2}\right)$ exposure for $5 \mathrm{~min}$. A $58.7^{\circ} \mathrm{C}$ temperature increase was observed at the tumor site $5 \mathrm{~min}$ after laser irradiation, proving a strong PTT potential (Lee et al., 2019).
Another sorbitol-conjugated NIR fluorophore (4Sorbitol-800) was designed by Yoo et al. to demonstrate tumor-targeting ability of sorbitol moieties and high PTT properties of heptamethine cyanine core (Figure 7). The temperature was elevated to $81.0^{\circ} \mathrm{C}$ in 4Sorbitol-800 solution $(100 \mu \mathrm{M})$ when irradiated with an $808 \mathrm{~nm}$ NIR laser $\left(1.1 \mathrm{~W} / \mathrm{cm}^{2}\right)$ for $1 \mathrm{~min}$. The photothermal conversion efficiency was calculated as $30.5 \%$. Additionally, in vitro PTT studies showed that it can produce efficient hyperthermia with NIR laser irradiation. Finally, HT-29 tumor-bearing mice were treated intravenously with the conjugate and the fluorescence signals were tracked for $24 \mathrm{~h}$ after injection. The signal peaked at $2 \mathrm{~h}$ and gradually decreased within the next $4 \mathrm{~h}$. The biodistribution was confirmed from renal and hepatic clearance at 4 and $24 \mathrm{~h}$ postinjection without significant uptake in other tissues. The in vivo PTT efficacy was evaluated by injecting 4Sorbitol-800 $(10 \mathrm{nmol}, 0.48 \mathrm{mg} / \mathrm{kg})$ into mice $2 \mathrm{~h}$ before laser treatment $\left(808 \mathrm{~nm}\right.$ laser at $1.1 \mathrm{~W} / \mathrm{cm}^{2}$ for $\left.5 \mathrm{~min}\right)$ and a $57.4^{\circ} \mathrm{C}$ temperature increase was observed. Treated mice showed no tumor recurrence for 7 days (Yoo et al., 2020).

The photostability problem and self-quenching property of cyanine-based photosensitizers can be minimized by incorporating an aggregation-induced emission (AIE) character to the PS. In this direction, Zhao et al. attached an AIE unit, namely, tetraphenylethene (TPE) into the structure of heptamethine cyanine IR780, which normally suffers from aggregation-caused quenching effect in high concentrations. Three different TPE-IR780 derivatives (IR780-OP-TPE, IR780O-TPE, and IR780-TPE) (Figure 7) via different linkage groups were synthesized and their properties were investigated. Because 

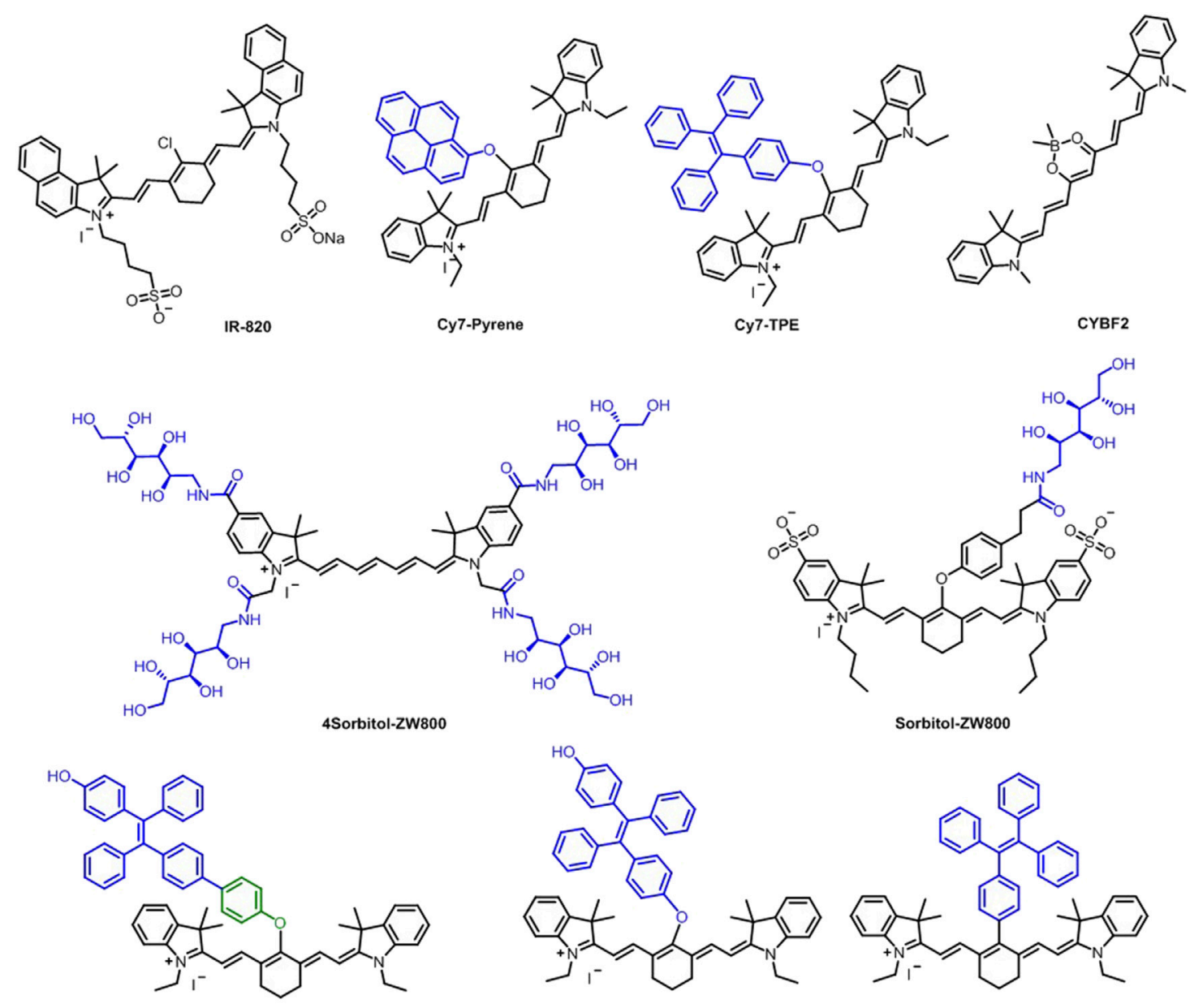

IR780-OP-TPE
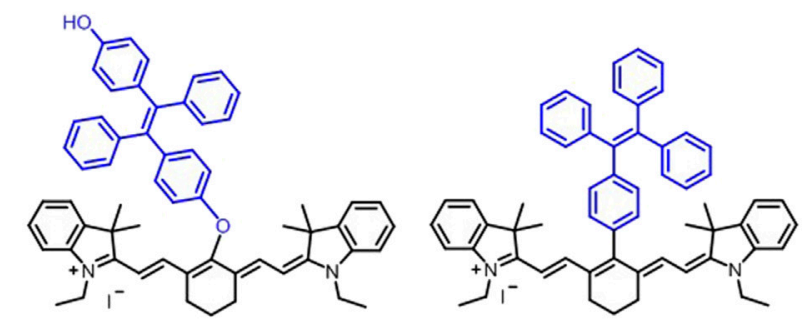

IR780-O-TPE

IR780-TPE

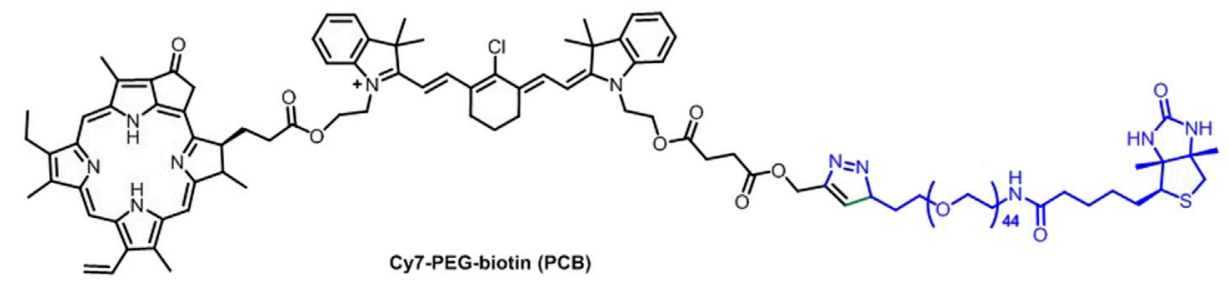

FIGURE 7 | Heavy atom-free cyanine-based phototherapy agents.

of its poor dispersibility in culture medium, IR780-TPE was not investigated in the cell studies. HeLa cells were incubated with both probes, and it was observed that the cells were "light-up" in 5 min of incubation, showing the ability for fluorescent imaging. The mitochondrial targeting ability of the conjugates were assessed using a mitochondrial-tracker green (MTG) dye, and results showed that the NIR signal from the probes overlapped with the green signal of the tracker. Furthermore, IR780-O-TPE was found to have a better photostability due to its enhanced aggregation in mitochondria. In vitro studies showed that the two variations of IR780 were more toxic to the cancer cells than normal cells, proving a potential to be used as selective therapeutic agents toward cancer cells. The PTT effect was then investigated under irradiation by an $808-\mathrm{nm}$ laser at $0.5 \mathrm{~W} / \mathrm{cm}^{2}$ for $10 \mathrm{~min}$ and 10 and $15^{\circ} \mathrm{C}$ temperature increase were recorded for IR780 and the three IR780 conjugates, respectively, at $50 \mu \mathrm{M}$ concentration. Late apoptotic cell death increased when the cells were treated with the probes $(0.6 \mu \mathrm{M}$, $24 \mathrm{~h}$ ) upon 5-min irradiation. Furthermore, in 4T1 tumorbearing mice, IR780-O-TPE was proved to have a more effective PTT response than IR780 itself, proposing an optimal photosensitizer (Zhao et al., 2020). 
A<smiles>[R2]N1/C(=C/C=C2\CCCC(/C=C/C3=C(C)C4(C)C=CC=CC4N3[R1])=C2Cl)C(C)(C)c2ccccc21</smiles><smiles></smiles>

1

$a a, b b, a b, a c, b c$<smiles>[R2]N1/C(=C/C=C2\CCCC(/C=C/c3c4n(n3[R2])-c3ccc(I)cc3C4(C)C)=C2Cl)C(C)(C)c2cc(I)ccc21</smiles>

2

$a a, b b, c c, a b, a c, b c$
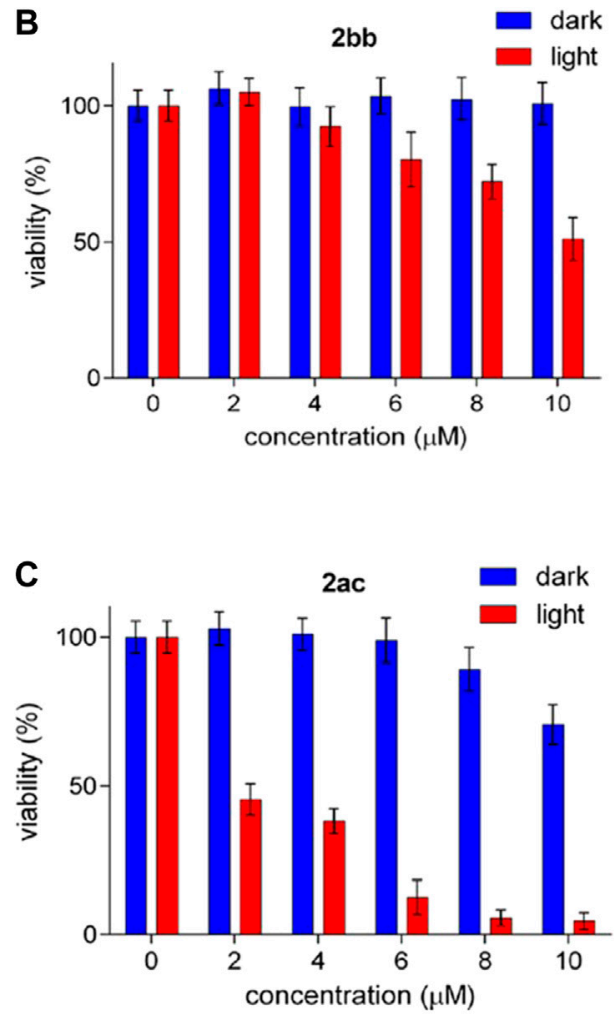

FIGURE 8 | (A) Structure of the cyanines derivatives (Oaa, bb, cc, 1aa, bb, ab, ac, bc, 2aa, bb, cc, ac, and bc), toxicity of (B) $2 \mathrm{bb}$ and (C) $2 \mathrm{ac}$ on HepG2 cells with and without laser irradiation. (Reproduced from ref. Usama et al. (2018) with permission from ACS, copyright 2018.)
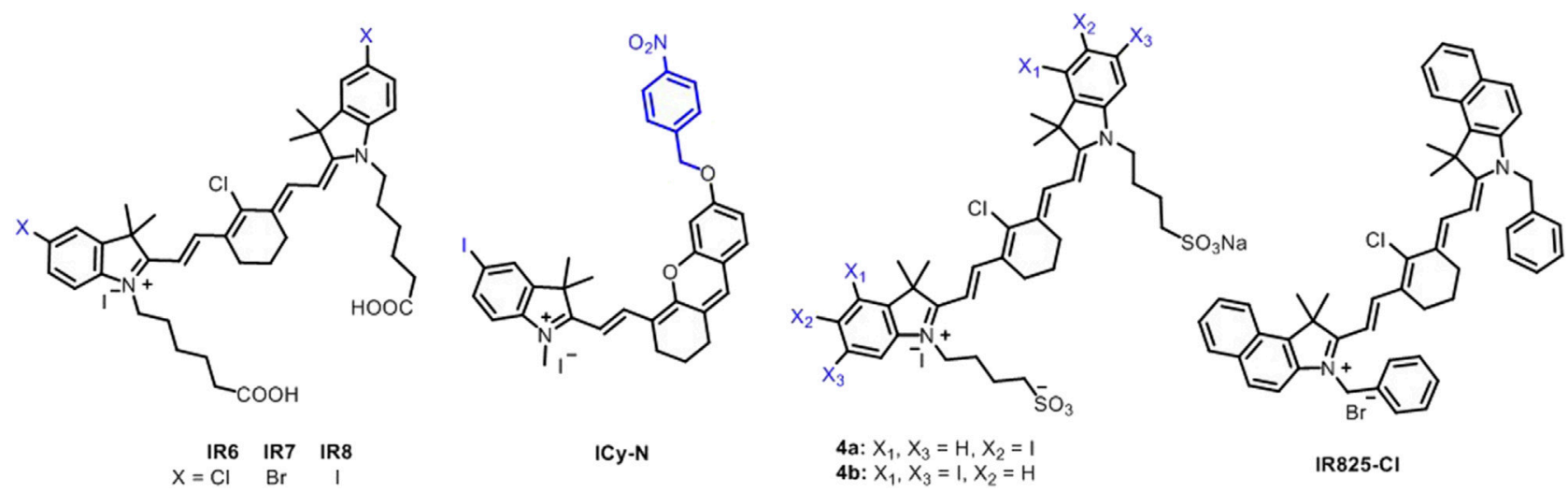

FIGURE 9 | Heavy atom-modified cyanine-based phototherapy agents.

$\mathrm{Wu}$ et al. synthesized two agents, namely, Cy7-pyrene and Cy7-TPE (Figure 7), by conjugating pyrene and tetraphenylethylene (TPE) moieties on Cy backbones to form well-organized $\mathrm{H}$-aggregates in aqueous solutions toward achieving high PTT efficiency. $\mathrm{H}$-aggregates of the fluorophores quench the fluorescence signal as it favors nonradiative transitions, which may result in PTT. This phenomenon is well studied in this work by introducing pyrene that is known to form strong $\pi-\pi$ stacking, resulting in $\mathrm{H}$-aggregation. However, the introduction of the TPE group, which was expected to inhibit $\pi-\pi$ stacking and $\mathrm{H}$-aggregation, was also shown to induce $\mathrm{H}$-aggregation without $\pi-\pi$ stacking and resulted in PTT effect. The photothermal conversion efficiency was calculated as 9.5 and $22.3 \%$ for Cy7-TPE and Cy7-pyrene, respectively. In vitro cytotoxicity was evaluated using HeLa cells and up to $100 \mu \mathrm{M}$ concentration was 

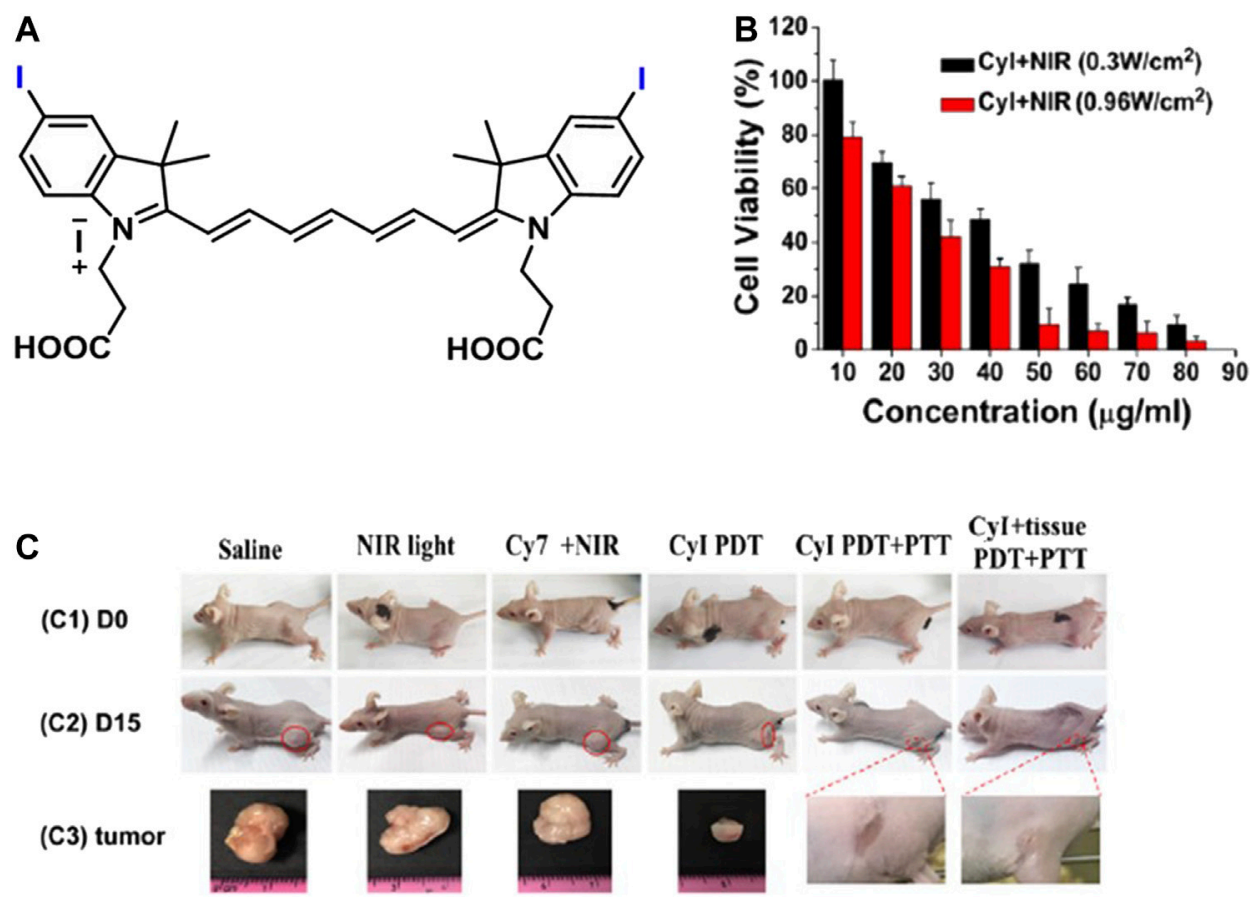

FIGURE 10 | (A) Representative structure of Cyl, (B) the effect of PDT (0.3 W/cm²) and PTT/PDT (0.96 W/cm²) on Cyl-treated HepG2 cells, and (C) images of mice before treatment (C1) and after different treatments (C2) and tumors after treatments (C3) in 15 days. (Reproduced from ref. Cao et al. (2019) with permission from ACS, copyright 2019.)

determined as nontoxic and biocompatible. With an 808-nm laser irradiation for $15 \mathrm{~min}$, almost all cells were dead. NIR fluorescence imaging-guided therapy was investigated using 4T1 tumor-bearing mice. Based on the data for the fluorescence signal from the tumors, $8-24 \mathrm{~h}$ after the injection was determined as the most suitable time range for the PTT. Furthermore, the mice were treated with an 808-nm laser for $15 \mathrm{~min} 8-24 \mathrm{~h}$ after the injection, and the real-time surface temperature of the tumors was monitored using IR thermal camera. Both the Cy7-pyrene and Cy7-TPE heated up to $60^{\circ} \mathrm{C}$ in less than $10 \mathrm{~min}$ of irradiation and in both groups, tumors were completely ablated (Wu et al., 2020).

In another study, hydrophobic pyropheophorbide A (Ppa) was covalently conjugated to Cy7-PEG-biotin (PCB) for image-guided PTT and PDT (Figure 7). The release of Ppa from PCB was studied in PBS and the total release of Ppa in PBS was less than $8 \%$ after 2 days at $\mathrm{pH}=7.4$. However, the irradiation of PCB at $808 \mathrm{~nm}$ provided $80 \%$ release in the first $10 \mathrm{~h}$. On the other hand, there was a little increase in release after $670 \mathrm{~nm}$ irradiation. Single $808 \mathrm{~nm}\left(0.5 \mathrm{~W} / \mathrm{cm}^{2}, 6 \mathrm{~min}\right)$ and $670 \mathrm{~nm}\left(20 \mathrm{~mW} / \mathrm{cm}^{2}\right.$, $6 \mathrm{~min}$ ) irradiations caused limited cell death on HepG2 cells, while combined PTT + PDT and PDT + PTT provided a significant cell death under same conditions. In addition, a combination of PTT + PDT provided more cell death than PDT + PTT due to high release of Ppa. The combination of PTT + PDT ablated tumor effectively compared to PDT + PTT (Xue et al., 2019).
Although cyanine derivatives have been utilized in PDT and synergistic PDT + PTT applications, they have very low singlet oxygen quantum yields, which causes inadequate efficacy in PDT and PDT + PTT actions. Therefore, phototherapies with cyanine dyes require high drug doses or high laser irradiation or long irradiation time for efficient results. Decorating cyanine cores with heavy atoms appeared as a promising solution to increase singlet oxygen production, improving spin-orbit coupling-mediated intersystem crossing (ISC).

\section{Heavy Atom-Modified Cyanine Dyes in Phototherapies}

Usama et al. developed 10 different near-IR fluorescent dyes, which contain zero, one, or two iodine atoms for photodynamic therapy under $780 \mathrm{~nm}$ irradiation and compared their potential with 2bb (literature control) (Figure 8A). The prepared compounds 2aa, 2ab, 2ac, and 2bc (Figure 8A) showed improved toxicity compared to $2 \mathrm{bb}$ after $10 \mathrm{~min}$ irradiation at $3.8 \mathrm{~mW} / \mathrm{cm}^{2}$ on HepG2 cells. More specifically, 2ac provided almost complete cell death at $10 \mu \mathrm{M}$, while $2 \mathrm{bb}$ caused less than $50 \%$ cell death (Figures $\mathbf{8 B}, \mathbf{C}$ ). The enhanced cytotoxicity occurred as a result of accumulation of these novel sensitizers in mitochondria. On the other side, $2 \mathrm{bb}$ was known to be accumulated in lysosome (Usama et al., 2018).

The effect of halogens (chlorine, bromine, and iodine) on phototherapy potential of heptamethine dye was evaluated on HeLa cells. All three halogenated dyes IR6 (chlorine), IR7 
A

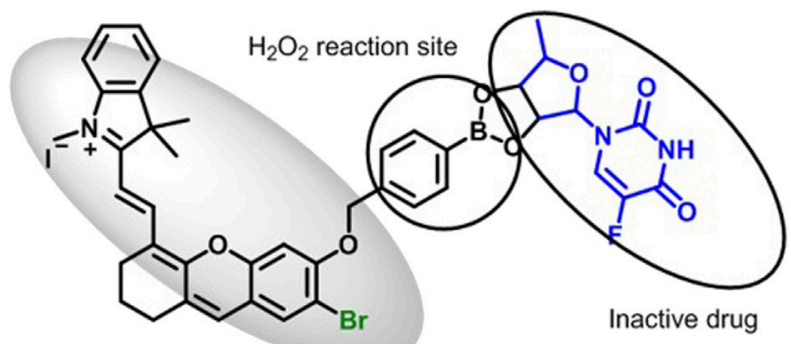

No fluorescence

Inhibited phototoxicity
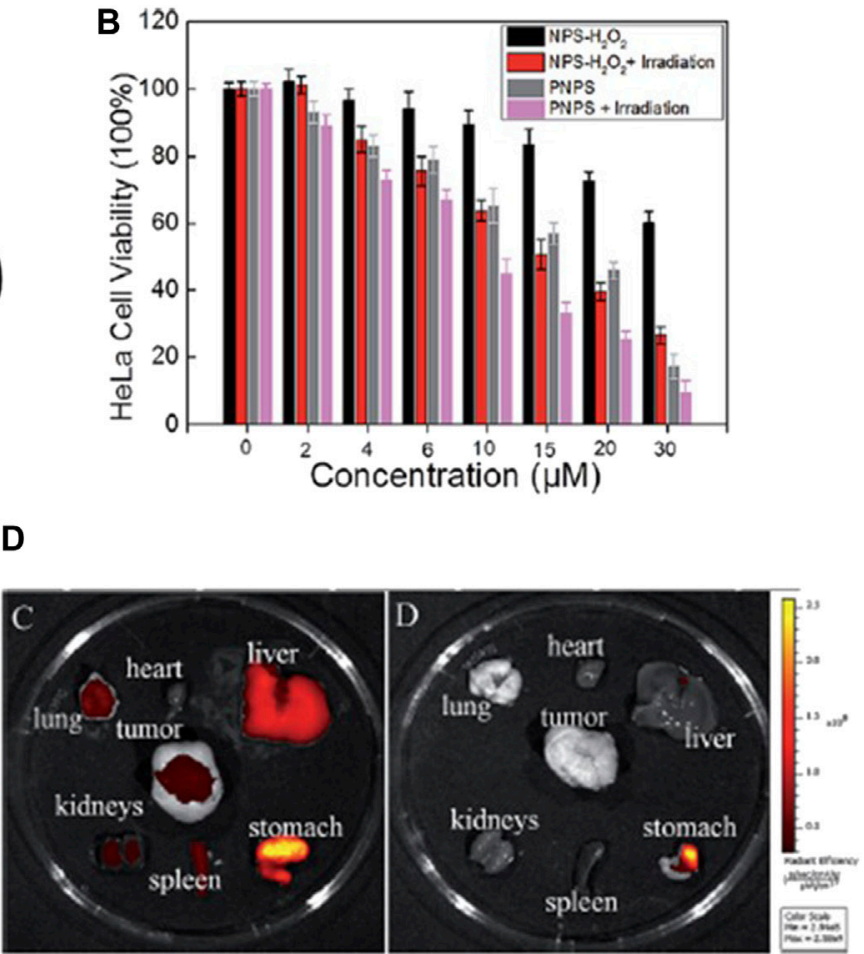

FIGURE 11 | (A) Representative design of PNPS, (B) the viability of HeLa cells after PNPS and PNPS + laser treatment, (C) in vivo imaging of HCT116 tumor-bearing mice after injection of saline and PNPS at different times, and (D) fluorescence images of different organs after injection of PNPS and saline at $25 \mathrm{~h}$. (Reproduced from ref. Liu et al. (2017) with permission from RSC, copyright 2017.)

(bromine), and IR8 (iodine) showed high singlet oxygen capacity and photothermal conversion efficiency (Figure 9). The photothermal conversion efficiency was $42.3,43.4$, and $46.6 \%$ for IR6, IR7, and IR8, respectively. IR8 showed enhanced photostability compared to IR6 and IR7 after multiple laser irradiations; however, there was still $8.7^{\circ} \mathrm{C}$ temperature loss between the first and last cycles. In addition, IR 8 provided more cell death than IR6 and IR7 after 5-min laser irradiation of $808 \mathrm{~nm}$ at $1 \mathrm{~W} / \mathrm{cm}^{2}$ having $\mathrm{IC}_{50}$ value at $16.2 \mu \mathrm{g} / \mathrm{ml}$ (Liu et al., 2021). NIR hemicyanine dye ICy-N was developed by modifying $\mathrm{Cy}-\mathrm{OH}$ with 4-nitrobenzyl bromide and iodine for hypoxia imaging and PDT (Figure 9). ICy-N has no fluorescence and low singlet oxygen quantum yield; however, the reduced product, ICy-OH, showed high singlet oxygen quantum yield and fluorescence potential, which occurred as a result of reduction of ICy-N by nitroreductase (NTR). $2.5 \mu \mathrm{M}$ ICy-N-treated 4T1 cells exhibited no fluorescence under normoxic conditions, while it induced strong fluorescence under hypoxia $(10 \%, 2 \%$, and $<1 \%$ $\mathrm{O}_{2}$ ) due to enhanced overexpression of NTR under hypoxic conditions. Irradiation of ICy-N (1.5 mM) with a $660-\mathrm{nm}$ laser irradiation at $12 \mathrm{~mW} / \mathrm{cm}^{2}$ for 5 min caused 20 and $80 \%$ cell death under 21 and $10 \% \mathrm{O}_{2}$ conditions, respectively. In vivo, there was no growth in tumor volume after the irradiation of ICy-N at $100 \mathrm{~mW} / \mathrm{cm}^{2}$ for $20 \mathrm{~min}$, while a 5 -fold increase was observed with only laser or ICy-N treatment (Xu et al., 2019).
Atchison et al. evaluated PDT efficiency of two iodinated derivatives of IR-783, di-iodinated (4a) or tetraiodinated (4b) in BxPC-3 and MIA-PaCa-2 pancreatic cells, and Ectopic BxPC-3 Luc pancreatic tumor after 1-min irradiation of 780-nm laser wavelength at $100 \mathrm{~mW}$ (Figure 9). There was no difference between $6 \mathrm{a}$ and $6 \mathrm{~b}$ in BxPC-3; however, $6 \mathrm{a}$ provided more cell deaths in MIA-PaCa-2. 6a induced more than 90 and $60 \%$ cell death in MIA-PaCa-2 and BxPC-3, respectively, at $50 \mu \mathrm{M}$. The irradiation of 6 a for 9 min caused almost total tumor elimination in vivo. However, a 39\% increase was observed in the tumor at day 11 (Atchison et al., 2017). A mitochondrial cyanine dye IR825-Cl was developed for red fluorescence imaging and PTT with $17.4 \%$ photothermal conversion efficiency (Figure 9). It induced $70 \%$ and more than $95 \%$ cell mortality at 5 and $8-20 \mu \mathrm{g} / \mathrm{ml}$ under an 808-nm laser irradiation at $1 \mathrm{~W} / \mathrm{cm}^{2}$ for $5 \mathrm{~min}$ on HeLa cells mostly through late apoptosis/necrosis (Pan et al., 2017). Synergistic PTT/PDT with iodine-modified NIR dye CyI (Figure 10A) resulted in $95.42 \pm 8.1 \%$ cell death in HepG2 cells after 1 -min irradiation of $808 \mathrm{~nm}$ at $0.96 \mathrm{~W} / \mathrm{cm}^{2}$, while PDT alone induced only $64.4 \pm 5.9 \%$ at $0.3 \mathrm{~W} / \mathrm{cm}^{2}$ (Figure 10B). In vivo, the total inhibition rate was $100 \%$ and $39.8 \%$ after synergistic PTT/PDT and PDT alone, respectively. The total inhibition rate was still $100 \%$ after synergistic PTT/PDT when the tumor was covered with $1-\mathrm{cm}$ pork tissues (Figure 10C) (Cao et al., 2019). 

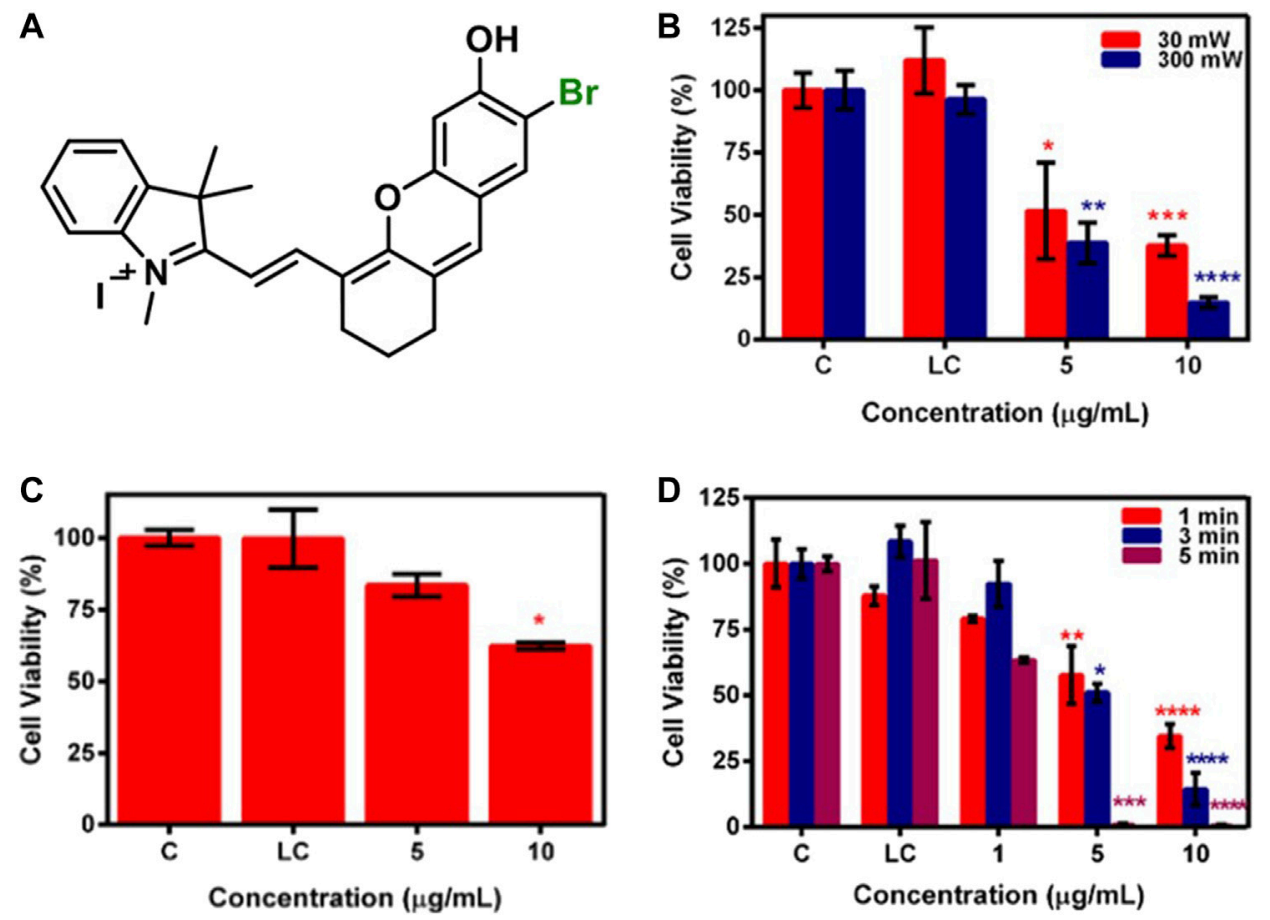

FIGURE 12 | (A) Representative structure of brominated hemicyanine (HC-1), cell viability of brominated hemicyanine treated SW480 cell line after (B) 640 nm, (C) $808 \mathrm{~nm}$, and (D) $640+808 \mathrm{~nm}$ laser irradiation. Reproduced from ref. Gunduz et al. (2021) with permission from Elsevier, copyright 2021.

TABLE 1 | Cell death results in phototherapy of heavy atom-modified cyanine dyes.

\begin{tabular}{|c|c|c|c|c|c|c|c|c|}
\hline Sample & $\begin{array}{l}\text { Type } \\
\text { of action }\end{array}$ & $\begin{array}{l}\text { Cell } \\
\text { type }\end{array}$ & $\begin{array}{c}\text { Irradiation } \\
\text { wavelength } \\
(\mathrm{nm})\end{array}$ & $\begin{array}{l}\text { Irradiation } \\
\text { time } \\
\text { (min) }\end{array}$ & $\begin{array}{c}\text { Irradiation } \\
\text { power } \\
\text { density }\end{array}$ & Concentration & $\begin{array}{c}\text { Cell } \\
\text { death } \\
(\%)\end{array}$ & Ref \\
\hline $2 b b$ & PDT & HepG2 & 780 & 10 & $3.8 \mathrm{~mW} / \mathrm{cm}^{2}$ & $10 \mu \mathrm{M}$ & Complete & Usama et al. (2018) \\
\hline IR8 & PDT + PTT & HeLa & 808 & 5 & $1 \mathrm{~W} / \mathrm{cm}^{2}$ & $100 \mu \mathrm{g} / \mathrm{ml}$ & $\approx 90$ & Liu et al. (2021) \\
\hline ICy-N & PDT & 4T1 & 660 & 5 & $12 \mathrm{~mW} / \mathrm{cm}^{2}$ & $1.5 \mathrm{mM}$ & 80 & Xu et al. (2019) \\
\hline lodinated derivative of IR-783 & PDT & $\begin{array}{l}\text { BxPC-3 } \\
\text { MIA- } \\
\text { PaCa-2 }\end{array}$ & 780 & 1 & $100 \mathrm{~mW}$ & $50 \mu \mathrm{M}$ & $\begin{array}{c}>90 \\
60\end{array}$ & Atchison et al. (2017) \\
\hline PNPS & PDT + Chemo & $\begin{array}{l}\text { HeLa } \\
\text { HepG2 }\end{array}$ & White light & 180 & $50 \mathrm{~W}$ & $30 \mu \mathrm{M}$ & $\begin{array}{l}\approx 90 \\
>90\end{array}$ & Liu et al. (2017) \\
\hline Cyl & $\begin{array}{l}\text { PDT } \\
\text { PTT + PDT }\end{array}$ & $\begin{array}{l}\text { HepG2 } \\
\text { HepG2 }\end{array}$ & $\begin{array}{l}808 \\
808\end{array}$ & $\begin{array}{l}1 \\
1\end{array}$ & $\begin{array}{c}0.3 \mathrm{~W} / \mathrm{cm}^{2} \\
0.96 \mathrm{~W} / \mathrm{cm}^{2}\end{array}$ & $\begin{array}{l}50 \mu \mathrm{g} / \mathrm{ml} \\
50 \mu \mathrm{g} / \mathrm{ml}\end{array}$ & $\begin{array}{l}65 \\
95\end{array}$ & $\begin{array}{l}\text { Cao et al. (2019) } \\
\text { Cao et al. (2019) }\end{array}$ \\
\hline $\begin{array}{l}\mathrm{IR} 825-\mathrm{Cl} \\
\mathrm{HC}-1\end{array}$ & $\begin{array}{l}\text { PTा } \\
\text { PTा + PDT }\end{array}$ & $\begin{array}{l}\text { HeLa } \\
\text { SW480 } \\
\text { HeLa }\end{array}$ & $\begin{array}{l}808 \\
640\end{array}$ & $\begin{array}{l}5 \\
5\end{array}$ & $\begin{array}{l}1 \mathrm{~W} / \mathrm{cm}^{2} \\
300 \mathrm{~mW}\end{array}$ & $\begin{array}{l}20 \mu \mathrm{g} / \mathrm{ml} \\
10 \mu \mathrm{g} / \mathrm{ml} \\
7.5 \mu \mathrm{g} / \mathrm{ml}\end{array}$ & $\begin{array}{c}>90 \\
85 \\
80\end{array}$ & $\begin{array}{l}\text { Pan et al. (2017) } \\
\text { Gunduz et al. (2021) }\end{array}$ \\
\hline & PTT + PDT & $\begin{array}{l}\text { SW480 } \\
\text { HeLa }\end{array}$ & 808 & 5 & $1000 \mathrm{~mW}$ & $\begin{array}{c}10 \mu \mathrm{g} / \mathrm{ml} \\
7.5 \mu \mathrm{g} / \mathrm{ml}\end{array}$ & $\begin{array}{l}38 \\
63\end{array}$ & Gunduz et al. (2021) \\
\hline & PTT + PDT & $\begin{array}{l}\text { SW480 } \\
\text { HeLa }\end{array}$ & $640+808$ & 5 & $300+1000 \mathrm{~mW}$ & $\begin{array}{c}10 \mu \mathrm{g} / \mathrm{ml} \\
7.5 \mu \mathrm{g} / \mathrm{ml}\end{array}$ & $\begin{array}{l}\text { Complete } \\
92\end{array}$ & Gunduz et al. (2021) \\
\hline
\end{tabular}

Liu et al. developed a mitochondria-targeted prodrug (PNPS) (Figure 11A) by conjugating $5^{\prime}$-deoxy-5-fluorouridine (5'-DFUR) and brominated hemicyanine for NIR imaging-guided and synergetic photodynamic-chemotherapy. A prodrug PNPS showed improved toxicity compared to commercial 5 '-DFUR on HeLa and HepG2 cells. In addition, the irradiation of PNPS under white light $(50 \mathrm{~W})$ reduced $\mathrm{IC}_{50}$ value from 16.6 and $14.8 \mu \mathrm{M}$ to 9.32 and $8.15 \mu \mathrm{M}$ for HeLa (Figure 11B) and HepG2 cells, respectively. PNPS-treated HCT116 tumor-bearing mice showed NIR fluorescence in the tumor after $1 \mathrm{~h}$ injection, indicating the release of activated drug (Liu et al., 2017) (Figures 9D, 11C).

In our previous work, we investigated PTT potential of brominated hemicyanine (Figure 12A) under a single (640 or $808 \mathrm{~nm})$ and dual laser $(640+808 \mathrm{~nm})$ irradiation in addition to 
TABLE 2 | In vivo results in phototherapy of heavy atom-modified cyanine dyes.

\begin{tabular}{|c|c|c|c|c|c|c|c|c|}
\hline Sample & $\begin{array}{c}\text { Type } \\
\text { of action }\end{array}$ & $\begin{array}{l}\text { Tumor } \\
\text { type }\end{array}$ & $\begin{array}{c}\text { Irradiation } \\
\text { wavelength } \\
\text { (nm) }\end{array}$ & $\begin{array}{l}\text { Irradiation } \\
\text { time } \\
\text { (min) }\end{array}$ & $\begin{array}{c}\text { Irradiation } \\
\text { power } \\
\text { density }\end{array}$ & $\begin{array}{l}\text { Injected } \\
\text { sample }\end{array}$ & $\begin{array}{c}\text { Inhibition } \\
\text { rate } \\
(\%)\end{array}$ & Ref \\
\hline $\begin{array}{l}\text { lodinated derivative of } \\
\text { IR-783 }\end{array}$ & PDT & $\mathrm{BxPC}-3$ & 780 & 9 & $100 \mathrm{~mW}$ & $2.5 \mathrm{mg} / \mathrm{kg}$ & $\approx 100$ & Atchison et al. (2017) \\
\hline ICy-N & PDT & $4 \mathrm{~T} 1$ & 660 & 20 & $100 \mathrm{~mW} / \mathrm{cm}^{2}$ & $50 \mu \mathrm{M}$ & $\approx 100$ & Xu et al. (2019) \\
\hline \multirow[t]{2}{*}{ Cyl } & PDT & HepG2 & 808 & 1 & $0.3 \mathrm{~W} / \mathrm{cm}^{2}$ & $1.5 \mathrm{mg} / \mathrm{kg}$ & 100 & Cao et al. (2019) \\
\hline & PTT + PDT & HepG2 & 808 & 1 & $0.96 \mathrm{~W} / \mathrm{cm}^{2}$ & $1.5 \mathrm{mg} / \mathrm{kg}$ & 100 & Cao et al. (2019) \\
\hline
\end{tabular}

its PDT potential. A 7.8-, 17-, and $21.6^{\circ} \mathrm{C}$ temperature increase was observed after 640,808 , and $640+808 \mathrm{~nm}$ laser irradiation, respectively. The photothermal conversion efficiency was calculated as $50 \%$ for $808 \mathrm{~nm}$ and $57 \%$ for $640 \mathrm{~nm}$. Both single 640 and $808 \mathrm{~nm}$ caused a significant cell death at 30 and $300 \mathrm{~mW}$ (Figure 12B) and $1,000 \mathrm{~mW}$ (Figure 12C) laser power, respectively, on HeLa and SW480 cell lines after 5-min irradiation. However, dual laser mode $(640 \mathrm{~nm} / 300 \mathrm{~mW}$, $0.78 \mathrm{~W} / \mathrm{cm}^{2}+808 \mathrm{~nm} / 1,000 \mathrm{~mW}, 2.6 \mathrm{~W} / \mathrm{cm}^{2}$ ) induced a significant cell death even after 1 - and 3-min irradiation and provided complete cell death on both cell lines after 5-min irradiation due to synergistic phototherapy (Figure 12D) (Gunduz et al., 2021).

Tables 1, 2 summarize the discussed phototherapy studies wherein heavy atom-modified cyanine dyes were used.

\section{CONCLUSIONS AND OUTLOOK}

In this mini-review, we summarized the recent studies on cyanine dye-based PDT and PTT. Although PDT and PTT offer many advantages over other techniques, the combination of the two brings about a strong synergism that makes the phototherapies applicable over a variety of tumor types. In doing so, finding a single PS that can perform both tasks, especially at a single and

\section{REFERENCES}

Agostinis, P., Berg, K., Cengel, K. A., Foster, T. H., Girotti, A. W., Gollnick, S. O., et al. (2011). Photodynamic Therapy of Cancer: an Update. CA: a Cancer J. clinicians 61, 250-281. doi:10.3322/caac.20114

Atchison, J., Kamila, S., Nesbitt, H., Logan, K. A., Nicholas, D. M., Fowley, C., et al. (2017). Iodinated Cyanine Dyes: a New Class of Sensitisers for Use in NIR Activated Photodynamic Therapy (PDT). Chem. Commun. 53, 2009-2012. doi:10.1039/c6cc09624g

Bharathiraja, S., Manivasagan, P., Santha Moorthy, M., Bui, N. Q., Jang, B., Phan, T. T. V., et al. (2018). Photo-based PDT/PTT Dual Model Killing and Imaging of Cancer Cells Using Phycocyanin-Polypyrrole Nanoparticles. Eur. J. Pharm. Biopharm. 123, 20-30. doi:10.1016/j.ejpb.2017.11.007

Bhattarai, P., and Dai, Z. (2017). Cyanine Based Nanoprobes for Cancer Theranostics. Adv. Healthc. Mater. 6, 1700262. doi:10.1002/adhm.201700262

Bilici, K., Muti, A., Demir Duman, F., Sennaroğlu, A., and Yağcı Acar, H. (2018). Investigation of the Factors Affecting the Photothermal Therapy Potential of Small Iron Oxide Nanoparticles over the 730-840 Nm Spectral Region. Photochem. Photobiol. Sci. 17, 1787-1793. doi:10.1039/c8pp00203g preferentially at NIR is critical in going forward in terms of cost and practicality. Cyanine dyes have appeared as promising in vivo phototherapy agents, which have demonstrated the ability to perform the combination of PTT and PDT as a single agent under laser irradiation. However, their poor singlet oxygen quantum yields limit the efficacy of the therapeutic outcome. Decoration of these dyes with heavy atoms substantially solved this issue and provided successful results at low concentrations, low irradiation powers, and short irradiation time. We believe that new-generation cyanine derivatives as effective phototherapy agents will continue to appear and more promising results will come by further improving the selectivity of these agents toward cancer cells. We also anticipate that studies that are aiming to investigate pharmacokinetics and pharmacodynamics of these agents are still needed in order to fasten the clinical translation of such designs.

\section{AUTHOR CONTRIBUTIONS}

$\mathrm{KB}, \mathrm{SC}$, and $\mathrm{EC}$ carried out the literature search. $\mathrm{KB}$ designed the figures and organized the literature search. SC drew the structures of molecules. All authors contributed to manuscript preparation and writing. SK and HY revised the manuscript and organized the study.

Bilici, K., Muti, A., Sennaroğlu, A., and Yagci Acar, H. (2019). Indocyanine green Loaded APTMS Coated SPIONs for Dual Phototherapy of Cancer. J. Photochem. Photobiol. B: Biol. 201, 111648. doi:10.1016/j.jphotobiol.2019.111648

Cao, J., Chi, J., Xia, J., Zhang, Y., Han, S., and Sun, Y. (2019). Iodinated Cyanine Dyes for Fast Near-Infrared-Guided Deep Tissue Synergistic Phototherapy. ACS Appl. Mater. Inter. 11, 25720-25729. doi:10.1021/acsami.9b07694

Celli, J. P., Spring, B. Q., Rizvi, I., Evans, C. L., Samkoe, K. S., Verma, S., et al. (2010). Imaging and Photodynamic Therapy: Mechanisms, Monitoring, and Optimization. Chem. Rev. 110, 2795-2838. doi:10.1021/cr900300p

Chen, Y., Li, L., Chen, W., Chen, H., and Yin, J. (2019). Near-infrared Small Molecular Fluorescent Dyes for Photothermal Therapy. Chin. Chem. Lett. 30, 1353-1360. doi:10.1016/j.cclet.2019.02.003

Chu, M., Shao, Y., Peng, J., Dai, X., Li, H., Wu, Q., et al. (2013). Near-infrared Laser Light Mediated Cancer Therapy by Photothermal Effect of Fe3O4 Magnetic Nanoparticles. Biomaterials 34, 4078-4088. doi:10.1016/ j.biomaterials.2013.01.086

Delaey, E., Van Laar, F., De Vos, D., Kamuhabwa, A., Jacobs, P., and De Witte, P. (2000). A Comparative Study of the Photosensitizing Characteristics of Some Cyanine Dyes. J. Photochem. Photobiol. B: Biol. 55, 27-36. doi:10.1016/s10111344(00)00021-x 
Deng, X., Shao, Z., and Zhao, Y. (2021). Solutions to the Drawbacks of Photothermal and Photodynamic Cancer Therapy. Adv. Sci. 8, 2002504. doi:10.1002/advs.202002504

Ding, Y., Ma, Y., Du, C., Wang, C., Chen, T., Wang, Y., et al. (2021). NO-releasing Polypeptide Nanocomposites Reverse Cancer Multidrug Resistance via Triple Therapies. Acta Biomater. 123, 335-345. doi:10.1016/j.actbio.2021.01.015

D. Martins, T., Lima, E., E. Boto, R., Ferreira, D., R. Fernandes, J., Almeida, P., et al. (2020). Red and Near-Infrared Absorbing Dicyanomethylene Squaraine Cyanine Dyes: Photophysicochemical Properties and Anti-tumor Photosensitizing Effects. Materials 13, 2083. doi:10.3390/ma13092083

Dolmans, D. E. J. G. J., Fukumura, D., and Jain, R. K. (2003). Photodynamic Therapy for Cancer. Nat. Rev. Cancer 3, 380-387. doi:10.1038/nrc1071

Dos Santos, A. L. F., De Almeida, D. R. Q., Terra, L. F., Baptista, M. C. S., and Labriola, L. (2019). Photodynamic Therapy in Cancer Treatment-An Update Review. J. Cancer Metastasis Treat. 5, 25. doi:10.20517/2394-4722.2018.83

Ebaston, T. M., Nakonechny, F., Talalai, E., Gellerman, G., and Patsenker, L. (2021). Iodinated Xanthene-Cyanine NIR Dyes as Potential Photosensitizers for Antimicrobial Photodynamic Therapy. Dyes Pigm. 184, 108854. doi:10.1016/j.dyepig.2020.108854

Feng, Z., Yu, X., Jiang, M., Zhu, L., Zhang, Y., Yang, W., et al. (2019). Excretable IR820 for In Vivo NIR-II Fluorescence Cerebrovascular Imaging and Photothermal Therapy of Subcutaneous Tumor. Theranostics 9, 5706-5719. doi:10.7150/thno.31332

Ferreira, D. P., Conceição, D. S., Ferreira, V. R. A., Graça, V. C., Santos, P. F., and Ferreira, L. F. V. (2013). Photochemical Properties of Squarylium Cyanine Dyes. Photochem. Photobiol. Sci. 12, 1948-1959. doi:10.1039/c3pp50132a

Gopika, G., Prasad, P. H., Lekshmi, A., Lekshmypriya, S., Sreesaila, S., Arunima, C., et al. (2021). Chemistry of Cyanine Dyes-A Review. Mater. Today Proc. doi:10.1016/j.matpr.2021.02.622

Gorman, A., Killoran, J., O’shea, C., Kenna, T., Gallagher, W. M., and O’shea, D. F. (2004). In Vitro demonstration of the Heavy-Atom Effect for Photodynamic Therapy. J. Am. Chem. Soc. 126, 10619-10631. doi:10.1021/ja047649e

Gunduz, H., Bilici, K., Cetin, S., Muti, A., Sennaroglu, A., Yagci Acar, H., et al. (2021). Dual Laser Activatable Brominated Hemicyanine as a Highly Efficient and Photostable Multimodal Phototherapy Agent. J. Photochem. Photobiol. B: Biol. 217, 112171. doi:10.1016/j.jphotobiol.2021.112171

Guo, R., Tian, Y., Wang, Y., and Yang, W. (2017). Near-Infrared Laser-Triggered Nitric Oxide Nanogenerators for the Reversal of Multidrug Resistance in Cancer. Adv. Funct. Mater. 27, 1606398. doi:10.1002/adfm.201606398

Habash, R. W., Bansal, R., Krewski, D., and Alhafid, H. T. (2006). Thermal Therapy, Part 1: an Introduction to thermal Therapy. Crit. Reviews ${ }^{\mathrm{TM}}$ Biomed. Eng. 34, 459-489. doi:10.1615/critrevbiomedeng.v34.i6.20

Habash, R. W., Bansal, R., Krewski, D., and Alhafid, H. T. (2007). Thermal Therapy, Part III: Ablation Techniques. Crit. Reviews ${ }^{\mathrm{TM}}$ Biomed. Eng. 35. 37-doi:10.1615/critrevbiomedeng.v35.i1-2.20

Hashemkhani, M., Bilici, K., Muti, A., Sennaroglu, A., and Acar, H. Y. (2020). Ag2S-Glutathione Quantum Dots for NIR Image Guided Photothermal Therapy. New J. Chem. 44, 5419-5427. doi:10.1039/c9nj04608a

He, R., Wang, Y.-C., Wang, X., Wang, Z., Liu, G., Zhou, W., et al. (2014). Facile Synthesis of Pentacle Gold-Copper alloy Nanocrystals and Their Plasmonic and Catalytic Properties. Nat. Commun. 5, 1-10. doi:10.1038/ ncomms5327

Hu, J.-J., Cheng, Y.-J., and Zhang, X.-Z. (2018). Recent Advances in Nanomaterials for Enhanced Photothermal Therapy of Tumors. Nanoscale 10, 22657-22672. doi:10.1039/c8nr07627h

Huang, X., and Luo, S. (2020). Heptamethine Cyanine-Based Small Molecular Cancer Theranostic Agents. Opt. Health Care Biomed. Opt. X: Int. Soc. Opt. Photonics, 11553. doi:10.1117/12.2573854

Jaque, D., Martínez Maestro, L., Del Rosal, B., Haro-Gonzalez, P., Benayas, A., Plaza, J. L., et al. (2014). Nanoparticles for Photothermal Therapies. Nanoscale 6, 9494-9530. doi:10.1039/c4nr00708e

Jędrzejewska, B., Kabatc, J., Pietrzak, M., and Pa̧Czkowski, J. (2003). Hemicyanine Dyes: Synthesis, Structure and Photophysical Properties. Dyes Pigm. 58, 47-58. doi:10.1016/s0143-7208(03)00035-4

Johannsen, M., Gneveckow, U., Eckelt, L., Feussner, A., WaldÖFner, N., Scholz, R., et al. (2005). Clinical Hyperthermia of Prostate Cancer Using Magnetic Nanoparticles: Presentation of a New Interstitial Technique. Int. J. hyperthermia 21, 637-647. doi:10.1080/02656730500158360
Jung, H. S., Lee, J.-H., Kim, K., Koo, S., Verwilst, P., Sessler, J. L., et al. (2017). A Mitochondria-Targeted Cryptocyanine-Based Photothermogenic Photosensitizer. J. Am. Chem. Soc. 139, 9972-9978. doi:10.1021/ jacs.7b04263

Jung, H. S., Verwilst, P., Sharma, A., Shin, J., Sessler, J. L., and Kim, J. S. (2018). Organic Molecule-Based Photothermal Agents: an Expanding Photothermal Therapy Universe. Chem. Soc. Rev. 47, 2280-2297. doi:10.1039/c7cs00522a

Ke, H., Wang, J., Dai, Z., Jin, Y., Qu, E., Xing, Z., et al. (2011). Gold-Nanoshelled Microcapsules: A Theranostic Agent for Ultrasound Contrast Imaging and Photothermal Therapy. Angew. Chem. Int. Ed. 50, 3017-3021. doi:10.1002/ anie.201008286

Kulbacka, J., Pola, A., Mosiadz, D., Choromanska, A., Nowak, P., Kotulska, M., et al. (2011). Cyanines as Efficient Photosensitizers in Photodynamic Reaction: Photophysical Properties and In Vitro Photodynamic Activity. Biochem. Mosc. 76, 473-479. doi:10.1134/s0006297911040110

Kulinich, A. V., and Ishchenko, A. A. (2009). Merocyanine Dyes: Synthesis, Structure, Properties and Applications. Russ. Chem. Rev. 78, 141-164. doi:10.1070/rc2009v078n02abeh003900

Kwiatkowski, S., Knap, B., Przystupski, D., Saczko, J., Kędzierska, E., Knap-Czop, K., et al. (2018). Photodynamic Therapy - Mechanisms, Photosensitizers and Combinations. Biomed. Pharmacother. 106, 1098-1107. doi:10.1016/ j.biopha.2018.07.049

Lan, M., Zhao, S., Liu, W., Lee, C. S., Zhang, W., and Wang, P. (2019). Photosensitizers for Photodynamic Therapy. Adv. Healthc. Mater. 8 , 1900132. doi:10.1002/adhm.201900132

Lee, S., Jung, J. S., Jo, G., Yang, D. H., Koh, Y. S., and Hyun, H. (2019). Nearinfrared Fluorescent Sorbitol Probe for Targeted Photothermal Cancer Therapy. Cancers 11, 1286. doi:10.3390/cancers11091286

León, F., Elizalde, P., Prieto, P., Sánchez-Migallón, A., Rodríguez, A. M., and De La Hoz, A. (2016). Bistriazine-based Streptocyanines. Preparation, Structural Determination and Optoelectronic Properties. Dyes Pigm. 131, 307-319. doi:10.1016/j.dyepig.2016.04.016

Li, Q., Tan, J., and Peng, B.-X. (1997). Synthesis and Characterization of Heptamethine Cyanine Dyes. Molecules 2, 91-98. doi:10.3390/20600091

Li, S., Sun, Z., Deng, G., Meng, X., Li, W., Ni, D., et al. (2017). Dual-modal ImagingGuided Highly Efficient Photothermal Therapy Using Heptamethine CyanineConjugated Hyaluronic Acid Micelles. Biomater. Sci. 5, 1122-1129. doi:10.1039/c7bm00230k

Li, W., Peng, J., Tan, L., Wu, J., Shi, K., Qu, Y., et al. (2016). Mild Photothermal Therapy/photodynamic Therapy/chemotherapy of Breast Cancer by Lyp-1 Modified Docetaxel/IR820 Co-loaded Micelles. Biomaterials 106, 119-133. doi:10.1016/j.biomaterials.2016.08.016

Li, X., Kolemen, S., Yoon, J., and Akkaya, E. U. (2017). Activatable Photosensitizers: Agents for Selective Photodynamic Therapy. Adv. Funct. Mater. 27, 1604053. doi:10.1002/adfm.201604053

Li, X., Kwon, N., Guo, T., Liu, Z., and Yoon, J. (2018a). Innovative Strategies for Hypoxic-Tumor Photodynamic Therapy. Angew. Chem. Int. Ed. 57, 11522-11531. doi:10.1002/anie.201805138

Li, X., Lee, S., and Yoon, J. (2018b). Supramolecular Photosensitizers Rejuvenate Photodynamic Therapy. Chem. Soc. Rev. 47, 1174-1188. doi:10.1039/ c7cs00594f

Li, X., Lovell, J. F., Yoon, J., and Chen, X. (2020). Clinical Development and Potential of Photothermal and Photodynamic Therapies for Cancer. Nat. Rev. Clin. Oncol. 17, 657-674. doi:10.1038/s41571-020-0410-2

Li, Y., Zhou, Y., Yue, X., and Dai, Z. (2020). Cyanine Conjugate-Based Biomedical Imaging Probes. Adv. Healthc. Mater. 9, 2001327. doi:10.1002/adhm.202001327

Li, Y., Zhou, Y., Yue, X., and Dai, Z. (2021). Cyanine Conjugates in Cancer Theranostics. Bioactive Mater. 6, 794-809. doi:10.1016/j.bioactmat.2020.09.009

Liang, L., Peng, S., Yuan, Z., Wei, C., He, Y., Zheng, J., et al. (2018). Biocompatible Tumor-Targeting Nanocomposites Based on CuS for Tumor Imaging and Photothermal Therapy. RSC Adv. 8, 6013-6026. doi:10.1039/c7ra12796k

Lima, E., E. Boto, R., Ferreira, D., R. Fernandes, J., Almeida, P., F. V. Ferreira, L., et al. (2020). Quinoline- and Benzoselenazole-Derived Unsymmetrical Squaraine Cyanine Dyes: Design, Synthesis, Photophysicochemical Features and Light-Triggerable Antiproliferative Effects against Breast Cancer Cell Lines. Materials 13, 2646. doi:10.3390/ma13112646

Liu, H.-W., Hu, X.-X., Li, K., Liu, Y., Rong, Q., Zhu, L., et al. (2017). A Mitochondrial-Targeted Prodrug for NIR Imaging Guided and Synergetic 
NIR Photodynamic-Chemo Cancer Therapy. Chem. Sci. 8, 7689-7695. doi:10.1039/c7sc03454g

Liu, H., Yin, J., Xing, E., Du, Y., Su, Y., Feng, Y., et al. (2021). Halogenated Cyanine Dyes for Synergistic Photodynamic and Photothermal Therapy. Dyes Pigm. 190, 109327. doi:10.1016/j.dyepig.2021.109327

Lucky, S. S., Soo, K. C., and Zhang, Y. (2015). Nanoparticles in Photodynamic Therapy. Chem. Rev. 115, 1990-2042. doi:10.1021/cr5004198

Luo, S., Tan, X., Fang, S., Wang, Y., Liu, T., Wang, X., et al. (2016). MitochondriaTargeted Small-Molecule Fluorophores for Dual Modal Cancer Phototherapy. Adv. Funct. Mater. 26, 2826-2835. doi:10.1002/adfm.201600159

Lv, S., Miao, Y., Liu, D., and Song, F. (2020). Recent Development of Photothermal Agents (PTAs) Based on Small Organic Molecular Dyes. ChemBioChem. 21 (15), doi:10.1002/cbic.202000089

Mallidi, S., Anbil, S., Bulin, A.-L., Obaid, G., Ichikawa, M., and Hasan, T. (2016). Beyond the Barriers of Light Penetration: Strategies, Perspectives and Possibilities for Photodynamic Therapy. Theranostics 6, 2458-2487. doi:10.7150/thno.16183

Matikonda, S. S., Helmerich, D. A., Meub, M., Beliu, G., Kollmannsberger, P., Greer, A., et al. (2021). Defining the Basis of Cyanine Phototruncation Enables a New Approach to Single Molecule Localization Microscopy. ChemRxiv.

Meng, X., Li, W., Sun, Z., Zhang, J., Zhou, L., Deng, G., et al. (2017a). Tumortargeted Small Molecule for Dual-Modal Imaging-Guided Phototherapy upon Near-Infrared Excitation. J. Mater. Chem. B 5, 9405-9411. doi:10.1039/ c7tb02496g

Meng, X., Yang, Y., Zhou, L., Zhang, l., Lv, Y., Li, S., et al. (2017b). Dual-responsive Molecular Probe for Tumor Targeted Imaging and Photodynamic Therapy. Theranostics 7, 1781-1794. doi:10.7150/thno.18437

Ming, L., Cheng, K., Chen, Y., Yang, R., and Chen, D. (2021). Enhancement of Tumor Lethality of ROS in Photodynamic Therapy. Cancer Med. 10, 257-268. doi:10.1002/cam4.3592

Mishra, A., Behera, R. K., Behera, P. K., Mishra, B. K., and Behera, G. B. (2000). Cyanines during the 1990s: a Review. Chem. Rev. 100, 1973-2012. doi:10.1021/ cr990402t

Narayanan, N., and Patonay, G. (1995). A New Method for the Synthesis of Heptamethine Cyanine Dyes: Synthesis of New Near-Infrared Fluorescent Labels. J. Org. Chem. 60, 2391-2395. doi:10.1021/jo00113a018

Pan, G.-Y., Jia, H.-R., Zhu, Y.-X., Wang, R.-H., Wu, F.-G., and Chen, Z. (2017). Dual Channel Activatable Cyanine Dye for Mitochondrial Imaging and Mitochondria-Targeted Cancer Theranostics. ACS Biomater. Sci. Eng. 3, 3596-3606. doi:10.1021/acsbiomaterials.7b00480

Santos, P. F., Reis, L. V., Duarte, I., Serrano, J. P., Almeida, P., Oliveira, A. S., et al. (2005). Synthesis and Photochemical Evaluation of Iodinated Squarylium Cyanine Dyes. Hca 88, 1135-1143. doi:10.1002/hlca.200590084

Shi, C., Wu, J. B., and Pan, D. (2016). Review on Near-Infrared Heptamethine Cyanine Dyes as Theranostic Agents for Tumor Imaging, Targeting, and Photodynamic Therapy. J. Biomed. Opt. 21, 050901. doi:10.1117/1.jbo.21.5.050901

Shindy, H. A. (Forthcoming 2012). Basics, Mechanisms and Properties in the Chemistry of Cyanine Dyes: a Review Paper. Mroc 9, 352-360. doi:10.2174/ 157019312804699528

Shindy, H. A. (2017). Fundamentals in the Chemistry of Cyanine Dyes: A Review. Dyes Pigm. 145, 505-513. doi:10.1016/j.dyepig.2017.06.029

Tan, X., Luo, S., Long, L., Wang, Y., Wang, D., Fang, S., et al. (2017). StructureGuided Design and Synthesis of a Mitochondria-Targeting Near-Infrared Fluorophore with Multimodal Therapeutic Activities. Adv. Mater. 29, 1704196. doi:10.1002/adma.201704196

Usama, S. M., Thavornpradit, S., and Burgess, K. (2018). Optimized Heptamethine Cyanines for Photodynamic Therapy. ACS Appl. Bio. Mater. 1, 1195-1205. doi:10.1021/acsabm.8b00414

Wang, Q., Xia, B., Xu, J., Niu, X., Cai, J., Shen, Q., et al. (2019). Biocompatible Small Organic Molecule Phototheranostics for NIR-II Fluorescence/photoacoustic Imaging and Simultaneous Photodynamic/photothermal Combination Therapy. Mater. Chem. Front. 3, 650-655. doi:10.1039/c9qm00036d
Wang, R., Li, X., and Yoon, J. (2021). Organelle-Targeted Photosensitizers for Precision Photodynamic Therapy. ACS Appl. Mater. Inter. 13, 19543-19571. doi:10.1021/acsami.1c02019

Wei, G., Yang, G., Wei, B., Wang, Y., and Zhou, S. (2019). Near-infrared Light Switching Nitric Oxide Nanoemitter for Triple-Combination Therapy of Multidrug Resistant Cancer. Acta Biomater. 100, 365-377. doi:10.1016/ j.actbio.2019.10.002

Weinberg, S. E., and Chandel, N. S. (2015). Targeting Mitochondria Metabolism for Cancer Therapy. Nat. Chem. Biol. 11, 9-15. doi:10.1038/nchembio.1712

Wu, F., Lu, Y., Mu, X., Chen, Z., Liu, S., Zhou, X., et al. (2020). Intriguing $\mathrm{H}$-Aggregates of Heptamethine Cyanine for Imaging-Guided Photothermal Cancer Therapy. ACS Appl. Mater. Inter. 12, 32388-32396. doi:10.1021/ acsami.0c07608

Xia, F., Niu, J., Hong, Y., Li, C., Cao, W., Wang, L., et al. (2019). Matrix Metallopeptidase 2 Targeted Delivery of Gold Nanostars Decorated with IR780 Iodide for Dual-Modal Imaging and Enhanced Photothermal/ photodynamic Therapy. Acta Biomater. 89, 289-299. doi:10.1016/ j.actbio.2019.03.008

Xu, F., Li, H., Yao, Q., Ge, H., Fan, J., Sun, W., et al. (2019). Hypoxia-activated NIR Photosensitizer Anchoring in the Mitochondria for Photodynamic Therapy. Chem. Sci. 10, 10586-10594. doi:10.1039/c9sc03355f

Xue, Y., Li, J., Yang, G., Liu, Z., Zhou, H., and Zhang, W. (2019). Multistep Consolidated Phototherapy Mediated by a NIR-Activated Photosensitizer. ACS Appl. Mater. Inter. 11, 33628-33636. doi:10.1021/acsami.9b10605

Yang, X., Bai, J., and Qian, Y. (2020). The Investigation of Unique Water-Soluble Heptamethine Cyanine Dye for Use as NIR Photosensitizer in Photodynamic Therapy of Cancer Cells. Spectrochimica Acta A: Mol. Biomol. Spectrosc. 228, 117702. doi:10.1016/j.saa.2019.117702

Yoo, Y., Jo, G., Jung, J. S., Yang, D. H., and Hyun, H. (2020). Multivalent Sorbitol Probes for Near-Infrared Photothermal Cancer Therapy. Part. Part. Syst. Charact. 37, 1900490. doi:10.1002/ppsc.201900490

Yuan, A., Wu, J., Tang, X., Zhao, L., Xu, F., and Hu, Y. (2013). Application of NearInfrared Dyes for Tumor Imaging, Photothermal, and Photodynamic Therapies. J. Pharm. Sci. 102, 6-28. doi:10.1002/jps.23356

Zhao, X., Fan, Z., Qiao, Y., Chen, Y., Wang, S., Yue, X., et al. (2020). AIEgens Conjugation Improves the Photothermal Efficacy and Near-Infrared Imaging of Heptamethine Cyanine IR-780. ACS Appl. Mater. Inter. 12, 16114-16124. doi:10.1021/acsami.0c01715

Zhao, X., Yang, Y., Yu, Y., Guo, S., Wang, W., and Zhu, S. (2019). A CyanineDerivative Photosensitizer with Enhanced Photostability for MitochondriaTargeted Photodynamic Therapy. Chem. Commun. 55, 13542-13545. doi:10.1039/c9cc06157f

Zhen, X., Zhang, J., Huang, J., Xie, C., Miao, Q., and Pu, K. (2018). Macrotheranostic Probe with Disease-Activated Near-Infrared Fluorescence, Photoacoustic, and Photothermal Signals for Imaging-Guided Therapy. Angew. Chem. 130, 7930-7934. doi:10.1002/ange.201803321

Zhou, L., Wu, Y., Luo, Y., Li, H., Meng, X., Liu, C., et al. (2019). MitochondriaLocalized Self-Reporting Small-Molecule-Decorated Theranostic Agents for Cancer-Organelle Transporting and Imaging. ACS Appl. Bio. Mater. 2, 5164-5173. doi:10.1021/acsabm.9b00811

Conflict of Interest: The authors declare that the research was conducted in the absence of any commercial or financial relationships that could be construed as a potential conflict of interest.

Copyright $\odot 2021$ Bilici, Cetin, Celikbas, Yagci Acar and Kolemen. This is an openaccess article distributed under the terms of the Creative Commons Attribution License (CC BY). The use, distribution or reproduction in other forums is permitted, provided the original author(s) and the copyright owner(s) are credited and that the original publication in this journal is cited, in accordance with accepted academic practice. No use, distribution or reproduction is permitted which does not comply with these terms. 